Canadian

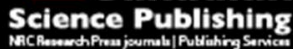

Canadian Geotechnical Journal Revue canadienne de géotechnique

Integrated approaches for predicting soil-water characteristic curve and resilient modulus of compacted fine-grained subgrade soils

\begin{tabular}{|r|l|}
\hline Journal: & Canadian Geotechnical Journal \\
\hline Manuscript ID & cgj-2016-0349.R2 \\
\hline Danuscript Type: & Article \\
\hline Complete List of Authors: & $\begin{array}{l}\text { Han, Zhong; Wuhan University, Civil Engineering; University of Ottawa, } \\
\text { Civil Engineering } \\
\text { Vanapalli, Sai K.; Wuhan University, Civil Engineering; University of } \\
\text { Ottawa, Civil Engineering } \\
\text { Zou, Wei-lie; Wuhan University, Civil Engineering }\end{array}$ \\
\hline Keyword: & $\begin{array}{l}\text { Soil-water characteristic curve, resilient modulus, moisture content, } \\
\text { pavement subgrade }\end{array}$ \\
\hline \multicolumn{2}{|c}{} \\
\hline
\end{tabular}

SCHOLARONE

Manuscripts 


\title{
Integrated approaches for predicting soil-water characteristic curve and resilient modulus of compacted fine-grained subgrade soils
}

\author{
Zhong $\operatorname{Han}^{1,2}$, Sai K. Vanapalli ${ }^{1,2}$ and Wei-lie Zou ${ }^{1}$ \\ ${ }^{1}$ School of Civil Engineering, Wuhan University, Wuhan, Hubei, 430072, China \\ ${ }^{2}$ Department of Civil Engineering, University of Ottawa, Ottawa, ON, K1N 6N5, Canada \\ Corresponding author: Sai K. Vanapalli (email: sai.vanapalli@uottawa.ca)
}

A revised manuscript submitted to Canadian Geotechnical Journal for review and publication December $2^{\text {nd }} 2016$ 


\section{ABSTRACT}

This paper combines a series of approaches for predicting the soil-water characteristic curve (SWCC) and the variation of the resilient modulus $\left(M_{R}\right)$ of compacted fine-grained subgrade soils with moisture content, which are the key information required in the mechanistic pavement design methods. The presented approaches for the SWCC and the $M_{R}$ are integrated as (i) they are developed following the same philosophy, (ii) they require only the measurements of the suction and moisture content or $M_{R}$ at saturated and optimum moisture content conditions for prediction and (iii) the predicted SWCC is used for predicting the $M_{R}$ - moisture content relationship. Experimental studies have been performed on five fine-grained subgrade soils which were collected from different regions in Ontario, Canada to determine their $M_{R}$ at various external stress levels and post-compaction moisture contents, as well as their SWCCs after the $M_{R}$ tests. Experimental measurements are predicted using the integrated approaches and the empirical approaches currently used in the mechanistic-empirical pavement design guide (MEPDG). It is demonstrated that the integrated approaches are easy to use and show improved reliability in predicting both the SWCC and $M_{R}$ for the investigated subgrade soils in spite of using limited experimental data.

\section{KEYWORDS}

Soil-water characteristic curve, resilient modulus, moisture content, pavement subgrade. 


\section{RÉSUMÉ}

Cet article combine une série d'approches pour prédire la courbe de rétention d'eau (CRE) et la variation du module élastique $\left(M_{R}\right)$ des sous-couches de sols fins compacts avec une certaine humidité. Celles-ci sont les informations clés requises pour les Méthodes de conception mécanique du revêtement. Les approches présentées pour le CRE et le $M_{R}$ sont intégrées en tenant compte des conditions suivantes (i) elles sont développées selon la même philosophie, (ii) elles ne nécessitent que des mesures de la succion et de la teneur en humidité ou du $M_{R}$ dans les conditions saturées et celles de la teneur en eau optimale pour la prédiction et (Iii) le CRE prédit est utilisé pour prédire la relation $M_{R}$ - teneur en humidité. Des études expérimentales ont été effectuées sur cinq sols fins des sous-couches, qui ont été recueillis dans différentes régions en Ontario, au Canada, afin de déterminer leur $M_{R}$ à différents niveaux de contraintes (pressions) stress externes et de teneur en humidité post-compactage. Les mesures expérimentales sont prédites à l'aide des approches intégrées et des approches empiriques actuellement utilisées dans le guide de conception mécanique-empirique des chaussées (MEPDG). Il est démontré que les approches intégrées sont faciles à utiliser et montrent une fiabilité améliorée dans la prévision à la fois du CRE et du $M_{R}$ pour les sols de sous-sols étudiés malgré l'utilisation de données expérimentales limitées.

\section{MOTS-CLÉS}

Courbe de rétention d'eau, module réversible, teneur en eau, sol de fondation 


\section{INTRODUCTION}

Pavements are layered structures typically formed with compacted granular materials placed over compacted subgrade soils and sealed with flexible and / or rigid surfacing. A major failure criterion used in mechanistic design methods for flexible pavements is the fatigue cracking that initiates at the bottom of the surfacing which is related to the local tensile strain and the elastic modulus of the surfacing materials (Huang et al. 2004). Tensile strain at the bottom of the surfacing layer due to the formation of the deflection basin under wheel loads is calculated using elastic theory by assuming that the base, subbase and subgrade layers are essentially elastic. The resilient modulus $\left(M_{R}\right)$ represents the material stiffness under cyclic loading conditions and is defined as the ratio of the cyclic deviator stress $\left(\sigma_{d}\right)$ to the resilient strain $\left(\varepsilon_{r}\right)$. The $M_{R}$ is practically used as the elastic modulus of pavement materials and therefore is the key material property for analyzing the deformation of pavement layers and the resulting tensile strain at the bottom of the surfacing layer (Zapata et al. 2007; Malla and Joshi 2008; Ng et al. 2013; Han and Vanapalli 2016a).

Pavement base course materials and subgrade soils are typically compacted at optimum moisture content $\left(w_{\text {opt }}\right.$, subscript opt hereafter is used to indicate the corresponding soil properties or physical states at optimum moisture content condition) to achieve maximum dry density $\left(\rho_{d \max }\right)$ that assures better engineering performance such as higher stiffness and shear strength. The $M_{\text {Ropt }}$ of pavement materials and subgrade soils is conventionally determined and used in the design (Khoury and Zaman 2004; Azam et al. 2013; Li et al. 2015). Moisture content of compacted pavement materials during their service life can fluctuate seasonally due to environmental factors 
such as the surface infiltration and evaporation, freeze-thaw cycles and variation of the ground water table. Moisture changes significantly influence the $M_{R}$ of compacted pavement aggregate materials and subgrade soils. Typically, the $M_{R}$ increases with decreasing moisture content and decreases with increasing moisture content (Li and Selig 1994; Tian et al. 1998; LeKarp et al. 2000; Bilodeau and Doré 2012; Khoury et al. 2013; Li et al. 2015; Zou et al. 2015; Han and Vanapalli 2016a). Due to these reasons, the reliable determination of (i) the moisture content distribution and migration associated with various environmental factors and (ii) the resulting changes in $M_{R}$ of pavement materials is required in the mechanistic pavement design methods.

As-compacted soils are initially in an unsaturated state. Their hydraulic and mechanical behavior should be interpreted within the framework of the mechanics of unsaturated soils using suction $(s)$ as the primary stress state variable (Fredlund 2006; Sheng 2011). The soil-water characteristic curve (SWCC) defines the relationship between the moisture content and suction. The SWCC and the permeability function form the fundamental constitutive relationship for the hydraulic analysis of unsaturated soils (Fredlund 2006; Qi and Vanapalli 2015). On the other hand, variation in the $M_{R}$ with moisture content can be interpreted and predicted by establishing the $M_{R}$ - $s$ relationships. Such an approach has been successfully used by several researchers for various pavement materials (Caicedo et al. 2009; Sawangsuriya et al. 2009; Cary and Zapata 2011; Ng et al. 2013; Gu et al. 2014; Nokkaew et al. 2014; Salour et al. 2014; Abu-Farsakh et al. 2015; Zou et al. 2015; Coronado et al. 2016). The current models developed based on the mechanics of unsaturated soils available in the literature for predicting $M_{R}-s$ relationships generally require the calibration of their model parameters. The calibration is based on regression analysis performed on extensive experimental measurements of the $M_{R}-s$ relationships at various $s$ and 
external stress levels. Detailed review and discussion on determining and predicting the $M_{R}-s$ relationships are available in Han and Vanapalli (2016a). The measurement of the SWCC and the variation of the $M_{R}$ with $s$ and moisture content however is cumbersome and time-consuming. There is a need for simple approaches that can be used to reliably predict the SWCC and $M_{R}$ using limited experimental data.

This paper combines two sets of approaches proposed for predicting the SWCC and the variation of the $M_{R}$ with respect to moisture content, respectively, for compacted fine-grained soils used as the subgrade for pavements. The combined approaches are referred to as integrated approaches in this study considering:

(i) Same philosophy is extended for both approaches; the focus of these approaches is to reduce the uncertainties in the predicted $s$ - moisture content (i.e. the SWCC) and the $M_{R}$ moisture content relationships using specific but limited experimental measurements;

(ii) For predicting the SWCC and the $M_{R}$, the required experimental measurements include the $s$ and $M_{R}$ at the same moisture contents (i.e. saturated moisture content and optimum moisture content);

(iii) The predicted SWCC can be used to predict the $M_{R}$ - moisture content relationships.

Comprehensive experimental studies have been performed to determine the $M_{R}$ at various external stress levels and moisture contents as well as the SWCCs after the $M_{R}$ tests for five subgrade soils collected from different regions of the province of Ontario in Canada. Experimental data are predicted using the integrated approaches as well as the empirical approaches currently used in the mechanistic-empirical pavement design guide (MEPDG) (ARA, 
Inc., ERES Consultants Division 2004). It is shown that the integrated approaches provide predictions of the $M_{R}$ and SWCC obtained after the $M_{R}$ testing for all five subgrade soils with improved reliability compared to the MEPDG approaches albeit that the integrated approaches and the MEPDG approaches require similar experimental measurements. The integrated approaches require limited and easy-to-obtain experimental data for prediction. Hence, they are simple and encouraging for use in the mechanistic pavement design methods to predict the hydraulic and mechanical behavior of unsaturated pavement materials.

\section{THEORETICAL BACKGROUND}

\section{Predicting the soil-water characteristic curve}

The soil-water characteristic curve (SWCC) defines the water retention capacity of soils upon the variation of suction. The water retention capacity of a soil can be described using several characteristics including (i) the air-entry suction $\left(s_{a e}\right)$ beyond which air starts to enter the soils' largest pores. The $s_{a e}$ separates the SWCC's boundary effect zone where soils remain in a state of capillary saturation and transition zone where soils start to desaturate; (ii) the slope of the SWCC in the transition zone which represents the rate of desaturation and (iii) the residual suction $\left(s_{\text {res }}\right)$ which separates the SWCC's transition zone and residual zone where liquid flow in soils' pores ceases (Vanapalli et al. 1999; Fredlund 2000; Zhai and Rahardjo 2013). Several analytical models available in the literature such as Equation 1 proposed by Fredlund and Xing (1994) can be used for fitting the SWCC. 


$$
\begin{gathered}
S_{r}=\frac{w}{w_{\text {sat }}}=C(s) \frac{1}{\left\{\ln \left[2.718+(s / a)^{n}\right]\right\}^{m}} \\
C(s)=\left[1-\frac{\ln \left(1+s / s_{\text {res }}\right)}{\ln \left(1+10^{6} / s_{\text {res }}\right)}\right]
\end{gathered}
$$

where $S_{r}$ is the degree of saturation, $w$ is the gravimetric water content, subscript sat hereafter is used to indicate the corresponding soil properties or physical states at saturated condition. It should be noted that the relationship $S_{r}=w / w_{\text {sat }}$ in Equation 1a is only valid for soils whose volumetric change (i.e. swelling or shrinkage) associated with the moisture content variation or the application of the external loading is insignificant. In other words, the soil has a constant void ratio $e$. This assumption is valid for non-plastic and low plastic soils; however, for soils with high plasticity or collapsing potential, the variation of $e$ on the SWCC should be considered (Zapata and Huston 2008). The model parameter $a$ indicates the $s_{a e}$ and model parameters $n$ and $m$ control the slope of the SWCC described by Equation 1. The $s_{\text {res }}$ is directly incorporated into Equation 1b. Equation $1 \mathrm{~b}$ facilitates the prediction of the entire SWCC (i.e. from $S_{r}=1.0$ at $s=$ 0 to $S_{r}=0$ at $s=10^{6} \mathrm{kPa}$ ) and ensures that the $S_{r}$ drops to 0 at $s=10^{6} \mathrm{kPa}$ (Fredlund and Xing 1994).

The $s_{a e}, s_{r e s}$ and slope of the SWCC of fine-grained soils have been correlated with soils' physical index properties (Leong and Rahardjo 1997; Zapata et al. 2000; Aubertin et al. 2003; Zhai and Rahardjo 2013). For example, Zapata (1999), based on experimental data of more than 
70 fine-grained soils, suggested to relate the wPI (i.e. wPI $=I_{p}(\%$ silt $+\%$ clay $) / 100$, where $I_{p}$ is the soil's plasticity index) to the $a, n, m$ and $s_{r e s}$ of Equation 1 using empirical Equation 2:

$$
\begin{gathered}
a=0.00364 \mathrm{wPI}^{3.35}+4 \mathrm{wPI}+11 \\
\frac{n}{m}=-2.313 \mathrm{wPI}^{0.14}+5 \\
m=0.0514 \mathrm{wPI}^{0.465}+0.5 \\
\frac{s_{\text {res }}}{a}=32.44 \exp (0.0186 \mathrm{wPI})
\end{gathered}
$$

Equation 2 is currently used in the MEPDG for estimating the SWCC for fine-grained soils. Similarly, Perera et al. (2005), based on experimental data of 63 cohesive soils, suggested another set of empirical relationships (Equation 3).

$$
\begin{gathered}
a=32.835 \ln (\mathrm{wPI})+32.438 \\
n=1.421 \mathrm{wPI}^{-0.3185} \\
m=-0.2154 \ln (\mathrm{wPI})+0.7145
\end{gathered}
$$




$$
s_{\text {res }}=500
$$

Empirical methods such as Equations 2 and 3 describe families of SWCC (i.e. collection of all possible SWCCs that can be described by specific equations) based on conventionally measured soil physical index properties (e.g., wPI). There are uncertainties associated with empirical methods: (i) SWCC is significantly influenced by soils' physical states such as the external stress, void ratio and structure in addition to physical index properties (Romero et al. 1999; Vanapalli et al. 1999; Ng and Pang 2000; Hu et al. 2013) and (ii) One soil may exhibit different SWCCs upon different hydraulic conditions (i.e. drying and wetting) due to hydraulic hysteresis (Fredlund 2000; Nuth and Laloui 2008; Gallipoli et al. 2015).

Several alternative approaches are available in the literature for predicting the SWCC (e.g., Sillers and Fredlund 2001; Fredlund et al. 2002; Simms and Yanful 2001; Catana et al. 2006; Houston et al. 2006; Chin et al. 2010; Sahin et al. 2014; Rahimi and Rahardjo 2016). Among them, there is a series of approaches that require a SWCC family and one measurement on the SWCC for prediction (e.g., Houston et al. 2006; Chin et al. 2010). The principle of these approaches is illustrated in Figure 1. Figure 1a shows in dashed lines the SWCC family described by Equation 3 differentiated by wPI values (Perera et al. 2005). Houston et al. (2006) suggested selecting the predicted SWCC using one measurement of $s$ - moisture content relationship instead of using the wPI. For example, if one measurement (say $S_{r}=0.6$ at $s=1000$ $\mathrm{kPa}$ as shown in Figure 1a) is available for a soil, the SWCC passing through this measurement, which is shown as a solid line, is the predicted SWCC for this soil. The required one measured point on the SWCC lies in the suction range of interest and is also measured at a specific soil 
physical state (e.g., density or void ratio, soil fabric, hydraulic and external stress conditions etc.). This approach to select the predicted SWCC is useful as it can partly take account of the influence of physical states and reduce the associated uncertainties. In fact, the predicted SWCC is bounded by the saturated point (i.e. $s=0 \mathrm{kPa}, S_{r}=0$ ) and one measured unsaturated point (e.g., $\left.s=1000 \mathrm{kPa}, S_{r}=0.6\right)$.

The key step in the Houston et al. (2006) approach is to determine the wPI value corresponding to the SWCC passing through the measured data point at an unsaturated condition. The wPI for the predicted SWCC may not necessarily be equal to the measured wPI value of the soil. Therefore, the wPI for the predicted SWCC using Houston et al. (2006) approach is noted as $x_{H}$ instead. A linear equation to determine the value of $x_{H}$ can be obtained by replacing wPI with $x_{H}$ in Equation 3 and substituting Equation 3 and the measured point (e.g., $s=1000 \mathrm{kPa}, S_{r}=0.6$ ) into Equation 1. For the case shown in Figure 1a, the predicted SWCC is described by Equation 3 using an $x_{H}$ value of 4.

The SWCC family described by Equation 2 (Zapata 1999) shown in dashed lines in Figure 1b can also be used along with one point of measured SWCC for prediction. This approach is based on Zapata (1999) SWCC family and hence is referred to the as the "Extended Zapata (1999)" approach. The wPI of the predicted SWCC is noted as $x_{Z}$ when using the extended Zapata (1999) approach. As shown in Figure 1b, the predicted SWCC (shown as a solid line) that passes through the same measurement has an $x_{Z}$ value of 25 . 
Similarly, Chin et al. (2010) proposed a SWCC family based on Equation 1 that is directly differentiated by $x_{C}$ (Equation 4) as shown in dashed lines in Figure 1c. Using the same procedure, an $x_{C}$ value of 240 can be determined which enables the predicted SWCC (shown as a solid line) to pass through the same measurement.

$$
\begin{gathered}
a=-2.4 x_{C}+722 \\
n=0.07 x_{C}^{0.4} \\
m=0.015 x_{C}^{0.7} \\
s_{\text {res }}=914 \exp \left(-0.002 x_{C}\right)
\end{gathered}
$$

Figure 1d shows the predicted SWCCs using Houston et al. (2006), Extended Zapata (1999) and Chin et al. (2010) methods. Predicted SWCCs show some differences which are more noticeable in the low suction range (typically $s<1000 \mathrm{kPa}$ ). The summarized approaches for predicting the SWCC (i.e. Extended Zapata 1999; Houston et al. 2006; Chin et al. 2010) are hereafter referred to as measurement-based approaches as measurements at one unsaturated condition are required. For predicting the SWCC of compacted pavement materials, the optimum moisture content condition, at which soil parameters (e.g. $s_{\text {opt }}$ at $S_{\text {ropt }}$ or $w_{\text {opt }}$ ) are conventionally determined, can be used as the required unsaturated condition. 
It should be noted that the measurement-based approaches cannot predict the hysteresis loop of the SWCC. They can only predict one SWCC based on one measurement of the $s$ - moisture content relationship, which could locate either on the main drying curve, or on the main wetting curve or on one of the scanning curves based on the hydraulic history of the soil. However, as the predicted SWCC passes through the measurement at unsaturated condition, the reliability of the predicted SWCC is relatively high in the simulation of the actual SWCC (i.e. main drying, or main wetting or scanning curve).

\section{Predicting the variation of $M_{R}$ with respect to moisture content}

The variation of the $M_{R}$ with respect to the moisture content (such as $S_{r}$ and $w$ ) is highly nonlinear, soil-type dependent and is influenced by many factors such as the external stress, soil structure and hydraulic hysteresis (Bilodeau and Doré 2012; Ng et al. 2013; Sivakumar et al. 2013; Han and Vanapalli 2016a). The $M_{R}$ - moisture content relationships in design practice are predicted using the empirical equations in light of their simplicity (Drumm et al. 1997; LeKarp et al. 2000; Malla and Joshi 2008; Cary and Zapata 2010). The MEPDG recommends the following empirical relationship to predict the $M_{R}-S_{r}$ relationships:

$$
\log \left(\frac{M_{R}}{M_{\text {Ropt }}}\right)=a_{0}+\frac{b-a_{0}}{1+\exp \left[\ln \left(-b / a_{0}\right)+k_{m}\left(S_{r}-S_{\text {ropt }}\right)\right]}
$$

where $a_{0}, b$ and $k_{m}$ are regression parameters. Parameter values $a_{0}=-0.5934, b=0.4, k_{m}=$ 6.1324 are suggested for fine-grained soils (ARA, Inc., ERES Consultants Division 2004). If 
constant $e$ and $S_{r}=w / w_{\text {sat }}$ are assumed, then $M_{R}-w$ relationships can be predicted using Equation 5.

The $M_{R}$ - moisture content relationship can also be interpreted and predicted within the framework of the mechanics of unsaturated soils. For example, Han and Vanapalli (2015) proposed Equation 6 to relate the $M_{R}$ to the $s, S_{r}$ and $w$ using one model parameter $\xi$.

$$
\frac{M_{R}-M_{\text {Rsat }}}{M_{\text {Ropt }}-M_{\text {Rsat }}}=\frac{s}{S_{\text {opt }}}\left(\frac{S_{r}}{S_{\text {ropt }}}\right)^{\xi}=\frac{s}{S_{o p t}}\left(\frac{w}{w_{o p t}}\right)^{\xi}
$$

Han and Vanapalli (2015) found a $\xi$ value of 2.0 suitable for 11 different fine-grained subgrade soils classified as (i) ML, MH, CL or $\mathrm{CH}$ as per the Unified Soil Classification System (ASTM D2487-11, ASTM 2011) or (ii) A-4, A-6, A-7 as per the American Association of State Highway and Transportation Officials soil classification system (AASHTO M145-91, AASHTO 2008). Han and Vanapalli (2016b) also showed that a $\xi=2.0$ provides reasonable predictions for 17 different cohesive fine-grained soils with clay content higher than $10 \%$ and / or plasticity index $\left(I_{p}\right)$ higher than 12. If the $\xi$ is assumed to be 2.0 for fine-grained subgrade soils and the $s$ corresponding to the $S_{r}$ or $w$ is estimated from the SWCC, Equation 6 can predict the $M_{R}-S_{r}$ or $M_{R}-w$ relationships using only the experimental data of $M_{R s a t}, M_{R o p t}, s_{\text {opt }}$ and $S_{\text {ropt }}$ or $w_{\text {opt }}$.

As a matter of fact, the predicted $M_{R}-S_{r}$ or $M_{R}-w$ relationships are bounded by the measurements at saturated condition (i.e. $M_{\text {Rsat }}$ ) and one unsaturated condition (i.e. optimum moisture content condition; $M_{\text {Ropt }}$ at $s_{\text {opt }}$ and $S_{\text {ropt }}$ or $\left.w_{\text {opt }}\right)$. This is the same as the philosophy of 
the measurement-based approaches detailed in the earlier section for predicting the SWCC. Predicted SWCCs using the measurement-based approaches can be used in Equation 6 for compacted subgrade soils. For such a scenario, only measurements at saturated condition and optimum moisture condition are required to predict both the SWCC and the $M_{R}$. Figure 2 illustrates the steps for predicting the SWCC and the $M_{R}$ - moisture content relationship using the introduced approaches.

The approaches shown in Figure 2 are integrated as they need measurements at the same moisture conditions and the SWCC predicted from Step 2 is also used in Equation 6 in Step 3 for predicting the $M_{R}$. These approaches can be used as an alternative for Equations 2 and 5, which are currently used in the MEPDG (ARA, Inc., ERES Consultants Division 2004), for predicting the SWCC and the $M_{R}$ - moisture content relationship of compacted subgrade soils. Table 1 compares the MEPDG approaches and the approaches introduced in this paper. The information required in the approaches introduced in this paper is similar to those needed in the MEPDG approaches with only two additional pieces of information, $M_{R s a t}$ and $s_{o p t}$, which can be measured using conventional equipment. The MEPDG approaches and the integrated approaches are used to predict the SWCC and $M_{R}$ - moisture content relationships measured for five different subgrade soils from Ontario, Canada.

\section{EXPERIMENTAL INVESTIGATIONS}

\section{Material and specimen preparation}


Five subgrade soils collected from different highway locations in Ontario (i.e. Kincardine lean clay, KLC; Sudbury lean clay, SLC; Toronto silty clay, TSC; Toronto lean clay, TLC; Ottawa lean clay, OLC) were tested to provide a database for the Ministry of Transportation of Ontario to facilitate the implementation of the MEPDG. The locations where these soils were collected are shown in Figure 3. Soil samples were collected from 0 to $3 \mathrm{~m}$ below natural ground table which is the typical depth of pavement subgrade layers (Konrad and Roy 2000; Doré and Zubeck 2008). Collected soil samples were air-dried, completely grinded, and then passed through $2 \mathrm{~mm}$ sieve to remove large size particles and other debris. Figure 4 shows gradation curves of the prepared soils derived from sieve analysis as per ASTM D6913-04 (ASTM 2009) and hydrometer analysis as per ASTM D422-63 (ASTM 2007). Figure 5 shows compaction curves of the prepared soils determined from standard Proctor tests as per ASTM D698-12 (ASTM 2012). Physical properties of the five prepared soils were also determined and summarized in Table 2.

Cylindrical specimens of $50 \mathrm{~mm}$ in diameter and $100 \mathrm{~mm}$ in height were used for cyclic triaxial loading tests. Specimens were statically compacted in a split brass mould with an inner diameter of $50 \mathrm{~mm}$. Oven-dried soil was carefully mixed with de-aired distilled water to achieve its $w_{\text {opt }}$ value summarized in Table 2. The prepared wet soil was passed through a $2 \mathrm{~mm}$ sieve again to remove large soil clods before compaction. Specimen was statically compacted in five equal layers with volume control such that each layer, and consequently the specimen was compacted to the $\gamma_{\text {dmax }}$ shown in Table 2. In total, eight specimens were compacted for each soil. Mass and volume measurements of the compacted specimens show that specimens of the same soil have similar initial void ratio and $\gamma_{d}$, which indirectly confirms an "identical" initial soil structure. 


\section{Moisture equilibrium}

The water content, $w$ of the compacted specimens was equilibrated from optimum water content, $w_{\text {opt }}$ to different higher or lower $w$ values before performing cyclic loading tests to investigate the influence of $w$ on the $M_{R}$. In North America, subgrade layers after construction are more likely to increase in moisture content. For example, Uzan (1998) found that clayey subgrade soils increase in the moisture content after pavement construction and reach an equilibrium condition with the external environment. Quintus and Killingsworth (1998) reported for 59 Long-Term Pavement Performance test sites with cohesive subgrade soils in USA that the in-situ moisture content of all sites stayed wet side of the $w_{\text {opt }}$. Due to these reasons, it was decided to focus on the behavior of the $M_{R}$ on the wet side of the $w_{\text {opt }}$. Among all the specimens of a soil, (i) one specimen was saturated to achieve $w_{\text {sat }}$, (ii) one specimen was kept at the $w_{\text {opt }}$, (iii) five specimens were wetted to different $w$ values between the $w_{\text {opt }}$ and $w_{\text {sat }}$ and (iv) one specimen was dried to a $w$ value lower than the $w_{\text {opt }}$. For regions where evaporation and drying are more commonly experienced, focus of experimental program however should be on the behavior of the $M_{R}$ on the dry side of the $w_{\text {opt }}$.

Whatman 42 filter papers were used to entirely wrap a specimen to alter its $w$. In order to saturate a specimen, the wrapped specimen was confined in a rubber membrane and placed onto a saturated ceramic disc to imbibe water. This procedure enables water movement into the specimen from the end placed on the ceramic disc and from the length of the specimen via the wetted filter papers. The rubber membrane ensures a close contact between the specimen and the filter papers. Rubber membrane and filter papers also protect the specimen from peeling off 
during the saturation process. The specimen was reversed at eight hour intervals and its mass was determined at 16 hour intervals. Saturation was assumed when the variation in the specimen's mass was less than $0.2 \mathrm{~g}(0.07-0.08 \%$ of the $w)$ between two consecutive measurements. The Skempton's B-test was performed prior to cyclic loading tests on the saturated specimens to verify the saturation. The lowest $\mathrm{B}$ value was found to be 0.96 from the testing program, which suggests that saturation has been achieved for all the saturated specimens.

In order to wet a specimen, de-aired distilled water was evenly sprayed on the filter papers wrapping the specimen. The amount of water sprayed each time was controlled at approximately $1.5 \mathrm{~g}$ (about $0.5 \%$ of the $w$ ). The specimen along with the filter papers was then tightly wrapped in plastic film and stored for a period of 24 hours to allow moisture equilibrium. The mass measurement of the specimen typically shows an increase of $0.2-0.3 \%$ in the $w$ of the specimen after 24 hours of equilibration. The wetting procedure continued until the desired $w$ was achieved. The procedure followed ensures a relatively low wetting rate which contributes to achievement of a uniform moisture distribution within the specimen. The drying procedure was conducted following the similar procedure except that air-dried filter papers were used instead of wet ones to wrap the specimens. The drying procedure used decreased the $w$ of the specimen also at a slow rate of $0.2 \%$ every 24 hours, which helped to avoid the possible development of shrinkage cracks during drying. No shrinkage cracks were observed on the dried or wetted specimens. Measurements on the specimens' dimension using a caliper after the wetting or drying suggest negligible volumetric changes (the maximum volumetric change was a volumetric expansion of $1.5 \%$ for the OLC s1 specimen which was totally saturated). This could be attributed to the reason that the tested soils are generally low plastic soils (see Table 2). All test specimens after 
achieving the desired $w$ values were sealed and stored for at least seven days to achieve moisture equilibrium before subjecting to cyclic loading tests. Table 3 summarizes the achieved $w$ in the specimens.

\section{Cyclic loading tests and suction measurement}

Cyclic loading tests were performed following AASHTO T307-99 (AASHTO 2003) testing protocols. Cyclic loadings were applied in a haversine form at a frequency of $1 \mathrm{~Hz} .1000$ cyclic loadings at a confining stress $\left(\sigma_{c}\right)$ of $41.4 \mathrm{kPa}$ and a deviator stress $\left(\sigma_{d}\right)$ of $27.6 \mathrm{kPa}$ were firstly applied on the specimen as a conditioning phase to minimize the imperfections of contacts between the loading cap or pedestal and the specimen. The loading phase followed which involved the application of $\sigma_{d}$ at levels of 27.6, 41.4, 55.2 and $68.9 \mathrm{kPa}$ on specimen confined under $\sigma_{c}$ levels of 41.4, 27.6 and $13.8 \mathrm{kPa}$. A total of 12 external stress levels (i.e. combinations of $\sigma_{d}$ and $\sigma_{c}$ ) were applied on each of the specimen and at least 100 cyclic loadings were applied under each external stress level. The $M_{R}$ of the specimen under a certain external stress level was determined as the ratio of the $\sigma_{d}$ to the average $\varepsilon_{r}$ of the specimen during the last five loadings.

The suction values in test specimens were measured using contact filter paper method following ASTM D5298-10 (ASTM 2010) protocols right after cyclic loading tests. Each of the test specimens was evenly sliced into four disks with flat ends. These four disks were used to get two sets of suction measurements using two of the sliced disks as a set. In other words, two disks were used to sandwich filter papers for the suction measurement. Seven days were allowed for the moisture equilibrium during which a pressure of $1 \mathrm{kPa}$ was applied to ensure reliable contact 
between the soil disks and filter papers (Power et al. 2008). The measured $s$ was deemed as the average $s$ of the two disks and for one specimen, two suction values were determined. The average $w$ of the two disks after performing the contact filter paper method was also measured. The average $w$ of the two disks is typically lower than the $w$ of the same specimen achieved before the cyclic loading tests using the procedures described in section "Moisture equilibrium" (listed in Table 3). This is due to the moisture loss during the operation of cyclic loading tests and filter paper methods. The $s$ (average $s$ of the two disks) - $w$ (average $w$ of the two disks) relationships measured from different specimens of the same soil can be used as the SWCC.

It should be noted that the obtained SWCC represents the $s-w$ relationships after the cyclic loading tests. It is reported that suction decreases during the application of cyclic loadings due to the accumulation of the plastic strain, the alteration in the soil fabric and the excitation of the excessive pore-water pressure (Sawangsuriya et al. 2009; Sivakumar et al. 2013). However, it would be difficult to measure or predict the transient suction during the cyclic loadings and relate them to the $M_{R}$ (Sivakumar et al. 2013; Cary and Zapata 2016). On the other hand, the conventional SWCC obtained from soils prior to cyclic loading tests cannot take into account of the influence of the cyclic loadings on the suction. For this reason, the suction measured after the cyclic loading tests has been successfully used to analyze the variation of the $M_{R}$ with suction and moisture content for different soils (Khoury and Zaman 2004; Sawangsuriya et al. 2009). Due to these reasons, the SWCCs obtained after the cyclic loading tests are used in the interpretation in this study.

\section{INTERPRETATION OF EXPERIMENTAL RESULTS}




\section{Soil-water characteristic curve}

The measured SWCCs for the five soils are shown in Figure 6. The measurements of suction values are consistent, highlighting the reliability of the contact filter paper method. There is an increase in the suction range covered by the SWCCs and a decrease in the slope of the SWCCs with an increase in the soils' plasticity index and clay content. This is consistent with other experimental observations reported in the literature (Zapata 1999; Vanapalli et al. 1999; Sillers and Fredlund 2001). It should be noted that:

(i) The $s-w$ relationships for one soil were measured from different specimens with "identical" initial soil structure and subjected to wetting / drying and cyclic loading tests. They represent approximate soil water retention behavior but may not explicitly reflect the influence of void ratio and structure changes arising from the wetting / drying and cyclic loading tests;

(ii) Specimens were compacted at $w_{\text {opt }}$ and $s_{\text {opt }}$ and then dried or wetted. Due to this reason, the measured $s-w$ relationships for the specimens are most likely to form a SWCC following the scanning path that lies between the main wetting path and drying path.

The fitted and predicted SWCCs are labelled in Figures 6 and 7 and Table 4 for easy distinction. Measured $s-w$ relationships for the five soils are fitted using the Fredlund and Xing (1994) equation (Equation 1) and are shown as solid lines in Figure 6 (labelled as 1). Table 4 summarizes model parameter values of Equation 1 for all the tested soils for which a unique $s_{\text {res }}$ 
value of $1500 \mathrm{kPa}$ is used following the suggestion of van Genuchten (1980). Suction levels of the specimens are determined from the fitted SWCCs shown in Figure 6 at the corresponding $w$ values of the specimens and are summarized in Table 3.

Empirical predictions using Equation 2 (Zapata 1999; labelled as 2) and Equation 3 (Perera et al. 2005; labelled as 3) are shown in Figure 6 in different broken lines. Model parameters values of Equation 1 predicted using Equations 2 and 3 are listed in Table 4. It can be observed that uncertainties in the empirical methods are apparent as some predictions are significantly different from the measurements. Figure 7 shows predicted SWCCs using the measurement-based approaches (i.e. extended Zapata 1999; labelled as 4; Houston et al. 2006; labelled as 5; Chin et al. 2010; labelled as 6) along with measured data that are best-fitted using Equation 1. Estimated model parameter values of Equation 1 along with the corresponding $x_{Z}, x_{H}$ and $x_{C}$ values are summarized in Table 4. The predicted SWCCs shown in Figure 7 are gathered and forced to pass through the measurements of $\left(s_{\text {opt }}, w_{\text {opt }}\right)$ and are close to the measured and fitted SWCCs. From comparisons shown in Figures 6 and 7, it can be concluded that the measurement-based approaches improve the reliability of the predicted SWCCs.

\section{Resilient modulus}

Measurements on the $M_{R}$ are interpreted with a stress-dependent model (Equation 7) used in the MEPDG (ARA, Inc., ERES Consultants Division 2004). This model relates the $M_{R}$ to the external stress condition (i.e. bulk stress $\theta$ and octahedral shear stress $\tau_{o c t} ; \theta=3 \sigma_{c}+\sigma_{d}$ and $\tau_{o c t}=$ 
$0.471 \sigma_{d}$ for conventional triaxial tests) using three model parameters $k_{1}, k_{2}$ and $k_{3}$ and the atmospheric pressure $p_{a}$.

$$
M_{R}=k_{1} p_{a}\left(\frac{\theta}{p_{a}}\right)^{k_{2}}\left(\frac{\tau_{o c t}}{p_{a}}+1\right)^{k_{3}}
$$

The $k_{1}, k_{2}$ and $k_{3}$ values for each specimen of the five different soils are determined from regression analysis and are listed in Table 3 along with the corresponding coefficient of determination $\left(\mathrm{R}^{2}\right)$ values. The representative resilient modulus $\left(M_{R \text { rep }}\right)$ values calculated for each specimen are summarized in Table 3. The $M_{\text {Rrep }}$ is calculated using Equation 7 and its model parameter values summarized in Table 3 at the mean confining and shearing stresses applied during the cyclic loading tests (i.e. $\sigma_{d}=48.2 \mathrm{kPa}$ and $\sigma_{c}=27.6 \mathrm{kPa}$, or $\theta=131 \mathrm{kPa}$ and $\left.\tau_{o c t}=22.7 \mathrm{kPa}\right)$. The $M_{R r e p}$ is the mean value of $M_{R}$ of a specimen over a particular external stress range and is used for design when the external stress levels are known but their influence on the $M_{R}$ is considered insignificant or is neglected for simplicity (Huang 2004). Figure 8 shows in symbols the variation of the measured $M_{\text {Rrep }}$ with $w$ for the five soils in the form of $\left(M_{\text {Rrep }} /\right.$ $\left.M_{\text {Rrep }, \text { sat }}\right)$ versus $\left(w-w_{\text {opt }}\right) /\left(w_{\text {sat }}-w_{\text {opt }}\right)$ relationships along with the soils' plasticity information (i.e. \%clay and $I_{p}$ ). The predicted $M_{\text {Rrep }}-w$ relationships using Equation 6 and fitted SWCCs by Equation 1 (i.e. SWCCs identified as KLC-1, SLC-1, TSC-1, TLC-1 and OLC-1 in Figures 6 and 7) are shown in solid lines. It should be noted that the five soils used in this study are similar to the fine-grained soils examined by Han and Vanapalli (2015) and Han and Vanapalli (2016b) in terms of soil classification, and \%clay and $I_{p}$ values (see Table 2). Therefore, a $\xi$ value of 2.0, 
which was suggested by Han and Vanapalli (2015) and Han and Vanapalli (2016b), is used in Equation 6 for all the five soils.

The measured $M_{\text {Rrep }}-w$ relationships are non-linear and sensitive to the soils' clay content and $I_{p}$. The sensitivity of the $M_{\text {Rrep }}$ to the $w$ increases with the clay content and $I_{p}$. For example, the $M_{\text {Rrep }}$ increases only $50 \%$ from $w_{\text {sat }}$ to $w_{\text {opt }}$ (i.e. $M_{\text {Rrep }, \text { opt }}=1.5 M_{\text {Rrep sat }}$ ) for the low plastic TSC. However, this increase is greater than $200 \%$ for the medium plastic soil TLC (i.e. $M_{\text {Rrep }, \text { opt }}>3$ $M_{\text {Rrep,sat }}$ ) and is approximately $450 \%$ for the high plastic OLC (i.e. $M_{\text {Rrep }, \text { opt }}=5.5 M_{\text {Rrep,sat }}$ ). These observations are consistent with results of other studies on the stiffness parameters reported in the literature (e.g., Drumm et al. 1997; Khoury et al. 2013; Hoyos et al. 2015). The predicted lines closely describe the non-linear evolution of the $M_{\text {Rrep }}$ with $w$ for all the soils. It should be noted that the predicted non-linearity bounded by the measurements of $M_{\text {Rrep,sat }}$ and $M_{\text {Rrep,opt }}$ is defined by Equation 6 using only the SWCC and fitting parameter $\xi=2$.

Figure 9 shows the comparisons between the measured $M_{\text {Rrep }}-w$ relationships (shown using symbols) and the predicted $M_{\text {Rrep }}-w$ relationships (i) using Equation 6 and the fitted SWCCs (shown as continuous lines), (ii) using Equation 6 and predicted SWCCs from measurementbased approaches (i.e. the integrated approaches; shown as different broken lines) and (iii) using MEPDG approach (i.e. Equation 5 with assumption of $S_{r}=w / w_{\text {sat }}$; shown as lines with symbols). It is observed that lean clays (KLC, TLC, SLC and OLC) show concave-up shaped $M_{\text {Rrep }}-w$ relationships while silty clay (TSC) shows a concave-down shaped $M_{\text {Rrep }}-w$ relationship. Predicted $M_{\text {Rrep }}-w$ relationships using Equation 6 and the SWCCs predicted from Extended Zapata (1999), Houston et al. (2006) or Chin et al. (2010) methods present similar non- 
linearity as is observed in the measurements as well as in the predictions using Equation 6 and the SWCCs fitted using Fredlund and Xing (1994) Equation (i.e. Equation 1). These predictions are close to the measurements and hence can be considered reasonable. Differences between these predictions may be attributed to the differences in the predicted SWCCs shown in Figure 7. On the other hand, predictions using the MEPDG method are reasonable for some soils such as the TSC and KLC while inconsistencies are observed for other soils. The slope of the predicted $M_{\text {Rrep }}-w$ relationships using the MEPDG method (Equation 5) for the tested lean clays is generally less steep compared to the measurements. Equation 5 uses constant model parameters and therefore predicts $M_{\text {Rrep }}-w$ relationships with the same slope for different soils. Due to this reason, varying sensitivities of the $M_{R}$ to the $w$ as presented in Figure 8 cannot be addressed. Some recent modifications to the MEPDG model can be used to consider the influence of soils' plasticity by incorporating wPI into Equation 5 (Zapata and Huston 2008; Cary and Zapata 2010).

It can be observed from Figure 9 that, despite the different SWCCs used for prediction, the variation of the $M_{R}$ on the wet side of the $w_{\text {opt }}$ is well predicted. On the other hand, the $M_{R}$ on the dry side of the $w_{\text {opt }}$ for some soils (for example, OLC and TSC) tends to be over-predicted using Equation 6. Therefore, caution and engineering judgement are recommended when predicting the $M_{R}$ on the dry side of the $w_{\text {opt }}$.

The influence of external stress levels can be taken into account by substituting Equation 7 into Equation 6 to express $M_{R s a t}$ and $M_{\text {Ropt }}$ using the corresponding $k_{1}, k_{2}$ and $k_{3}$ values summarized in Table 3. Figure 10 shows examples of predictions where measurements of $M_{R}-\sigma_{d}-w$ relationships of the five soils at a $\sigma_{c}$ level of $27.6 \mathrm{kPa}$ are shown in symbols and predictions are 
shown as 3-D surfaces. The SWCCs used in Equation 6 are predicted using Houston et al. (2006) method (i.e. SWCCs KLC-5, TLC-5, TSC-5, SLC-5 and OLC-5 detailed in Figure 7 and Table 4). It is noted that SWCCs predicted using other measurement based methods can also be used in Equation 6 for prediction. The predicted surfaces are smooth and vary with the $\sigma_{d}$ and $w$. They closely simulate the coupling between the $M_{R}$, external stress level and moisture content (i.e. $M_{R}$ - external stress level relationship is influenced by the moisture content and $M_{R}$ - moisture content external relationship is also influenced by the stress level) which is widely reported in the recent literature (Ng et al. 2013; Azam et al. 2013; Coronado et al. 2016). The measured and predicted $M_{R}$ is less sensitive to the $\sigma_{d}$ at higher $w$ level (e.g., $M_{R s a t}$ at $w_{s a t}$ ) and the sensitivity increases with decreasing $w$, presenting inclined non-linear $M_{R}-\sigma_{d}$ relationships (e.g., $M_{R o p t}$ at $w_{\text {opt }}$ ). It should be noted that the (i) SWCCs shown in Figure 7, (ii) $M_{\text {Rrep }}-w$ relationships shown in Figure 9 and (iii) $M_{R}-\sigma_{d}-w$ relationships shown in Figure 10 are predicted using the integrated approaches introduced in this study using only measurements at $w_{\text {opt }}$ and $w_{\text {sat }}$. Measurements at other $w$ levels are not required in the prediction procedure but are reasonably predicted as can be observed from Figures 7, 9 and 10.

Figure 11 shows an example, for $M_{R}-\sigma_{d}-w$ relationships of the SLC soil at $\sigma_{c}=27.6 \mathrm{kPa}$, the predictions provided by Equation 6 using fitted SWCC (Equation 1, see Figure 11a) and predicted SWCCs (using Zapata 1999 extended, Houston et al. 2006 and Chin et al. 2010 methods; see Figures 11b, 11c and 11d) and the predictions provided by MEPDG approach (Equation 5 where $M_{\text {Ropt }}$ is expressed using Equation 7 to take into account the external stress levels). Surfaces predicted by Equation 6 vary when different SWCCs are used. The reliability of the prediction depends on how close the predicted SWCC is to the measured SWCC. For 
example, the predicted SWCC for the SLC using Houston et al. (2006) approach (SLC-5 in Figure $7 b$ ) is closer to the measurements than that predicted using extended Zapata (1999) approach (SLC-4 in Figure 7b). Therefore, the predicted $M_{R}-\sigma_{d}-w$ surface using SLC-5 (Figure 11c) is closer to the measurements than the surface predicted using SLC-4 (Figure 11b). The surface predicted by the MEPDG Equation 5 however presents constant $M_{R}-\sigma_{d}$ relationship defined by Equation 7 for the $M_{\text {Ropt }}$ over the entire $w$ range. Figure 12 provides, for the five tested soils, comparisons between the measured $M_{R}$ and the predicted $M_{R}$ using (i) Equation 6 and SWCCs fitted by Equation 1, (ii) Equation 6 and SWCCs predicted from various measurement-based approaches and (iii) MEPDG Equation 5. The $\mathrm{R}^{2}$ values of predictions of Equation 6 are generally higher in comparison to Equation 5, suggesting an improved reliability. Variation in the $\mathrm{R}^{2}$ values for predictions of Equation 6 is associated with the reliability of the predicted SWCCs.

\section{SENSITIVITY OF THE APPROACHES}

As summarized in Table 1, the integrated approaches introduced in this study require the same information as is used in the MEPDG approaches (i.e. $M_{\text {Ropt }}, S_{\text {ropt }}, w_{\text {sat }}$ and $w_{\text {opt }}$ ) with two additional measurements: $M_{R s a t}$ and $s_{\text {opt }}$. The $M_{R s a t}, M_{\text {Ropt }}$ and moisture contents $\left(S_{r}\right.$ or $\left.w\right)$ can be measured with high reliability using conventional equipment. However, the measurement of suction (i.e. $s_{\text {opt }}$ ) is sensitive to many factors such as the stress level and history, temperature, soil fabric, hydraulic hysteresis and measuring device and procedure (Fredlund 2000; Ng and Pang 2000; Ridley et al. 2003; Leong et al. 2004; Power and Vanapalli 2010; Tarantino et al. 2011; 
Vanapalli and Oh 2011; $\mathrm{Ng}$ and Zhou 2014). Due to this reason, the $s_{\text {opt }}$ is identified as the key information and the sensitivity of the predictions to $s_{o p t}$ is discussed in this section.

The influence of the $s_{\text {opt }}$ on the predicted SWCC is straightforward. Changes in the $s_{\text {opt }}$ result in alternations in the $x_{Z}, x_{H}$ and $x_{C}$ values in the measurement-based methods. A decrease in the $s_{\text {opt }}$ leads to decreased $x_{Z}$ and $x_{H}$ while increased $x_{C}$ and vice versa. Figure 13 shows the variation of $a$, $n$ and $m$ for Equation 1 with the wPI $\left(x_{Z}\right.$ or $\left.x_{H}\right)$ and $x_{C}$ described by Zapata (1999) (Equation 2, Figure 13a), Perera et al. (2005) (Equation 3, Figure 13b) and Chin et al. (2010) (Equation 4, Figure 13c). Typical ranges for the wPI (for the $x_{Z}$ or $x_{H}$ as well) and $x_{C}$ are 0 to 50 and 0 to 300 , respectively (Zapata 1999; Chin et al. 2010).

As demonstrated in Figure 13a, the $n$ and $m$ vary considerably at low wPI or $x_{Z}$ range while the variation in $a$ is significant at high wPI or $x_{Z}$ range. This means that when using the extended Zapata (1999) approach, a low value of $s_{\text {opt }}$ corresponds to a low $x_{Z}$ value and a variation in the $s_{\text {opt }}$ results in (i) drastic changes in $n$ and $m$ and the slope of the predicted SWCC while (ii) a less pronounced change in the $a$ and the $s_{a e}$ of the predicted SWCC. For a high $s_{o p t}$ and therefore a high $x_{Z}$ value, the same variation in the $s_{\text {opt }}$ and $x_{Z}$ on the other hand, results in (i) a less pronounced change in the $n$ and $m$ and the slope of the predicted SWCC while (ii) a drastic change in the $a$ and $s_{a e}$ of the predicted SWCC. Similar analysis can be extended for (i) the $s_{o p t}$ and $x_{H}$ in Houston et al. (2006) approach as shown in Figure 13b and (ii) the $s_{o p t}$ and $x_{C}$ in Chin et al. (2010) approach as shown in Figure 13c to understand their influence on the $s_{a e}$ and the slope of the predicted SWCC. 
The influence of the $s_{\text {opt }}$ on the predicted SWCC is also extended to the predicted $M_{R}$ - moisture content relationship. Figure 14 shows an example, based on the measurements of the TLC, the influence of the SWCC parameters on the predicted $M_{\text {Rrep }}$ - moisture content relationship. Solid lines in Figure 14 represent the fitted SWCC using Equation 1 and the predicted $M_{\text {Rrep }}-w$ relationship using Equation 6 and the fitted SWCC. The different broken lines represent the SWCCs plotted using Equation 1 and varying $a, n$ and $m$ values (variations of $-50 \%,+50 \%$ and $+100 \%$ are applied to one of the $a, n$ and $m$ values while keeping the other two unchanged; i.e. Figure 14a shows the SWCCs with varying $a$ but constant $n$ and $m$, Figure $14 \mathrm{c}$ shows the SWCCs with varying $n$ but constant $a$ and $m$ and Figure 14e shows the SWCCs with varying $m$ but constant $a$ and $n$ ). The predicted $M_{\text {Rrep }}-w$ relationships using Equation 6 and the corresponding SWCCs are also shown in this figure. Different SWCCs assign different $s_{\text {opt }}$ values for the same $w_{\text {opt }}$ (note that the measured $s_{\text {opt }}$ and $w_{\text {opt }}$ for TLC are $108 \mathrm{kPa}$ and $12.3 \%$, respectively) as shown in Figures $14 \mathrm{a}, 14 \mathrm{c}$ and 14e. It can be observed from Figures 14b, 14d and $14 \mathrm{f}$ that the predicted $M_{\text {Rrep }}-w$ relationships show different sensitivities for the same variations with respect to the values of $a, n$ and $m$. The $M_{\text {Rrep }}-w$ relationships are highly sensitive to the values of $n$, followed by the $m$ values and are less sensitive to the values of $a$. In other words, the slope of the SWCC, which is controlled by $n$ and $m$, is the major factor influencing the predicted $M_{R}$ - moisture content relationships using Equation 6. As illustrated in Figure $13, n$ and $m$ vary drastically at lower wPI (also $x_{Z}$ or $x_{H}$ ) range and higher $x_{C}$ range. Therefore, it is suggested that: (i) when using extended Zapata (1999) and Houston et al. (2006) measurement-based approaches and Equation 6 for prediction, if the measured $s_{\text {opt }}$ is low (corresponds to low $x_{Z}$ and $x_{H}$ values), uncertainties (or changes) in the $s_{\text {opt }}$ measurement have more significant influence on the predicted $M_{R}$ - moisture content relationships and (ii) when 
using Chin et al. (2010) measurement-based approach, if the measured $s_{\text {opt }}$ is high (corresponds to low $x_{C}$ ), the influence of the uncertainties (or changes) in the $s_{\text {opt }}$ measurement is more significant.

Figure 15 shows examples of the sensitivity analysis based on measurements of KLC and TLC (shown in symbols). Houston et al. (2006) approach is used to predict the SWCCs for these two soils using their $s_{\text {opt }}$ and $w_{\text {opt }}$ values $\left(s_{\text {opt }}=67 \mathrm{kPa}, w_{\text {opt }}=20.3 \%\right.$ for the KLC and $s_{\text {opt }}=108 \mathrm{kPa}$, $w_{\text {opt }}=12.2 \%$ for the TLC). Variations of $-50 \%,+50 \%$ and $+100 \%$ are applied to the $s_{\text {opt }}$ of KLC and TLC as shown in Figures 15a and 15c. The respective $x_{H}$ values for the varying $s_{\text {opt }}$ along with the predicted SWCCs (shown in lines) are shown in Figures 15a and 15c. The predicted $M_{\text {Rrep }}-w$ relationships using the predicted SWCCs and Equation 6 are shown in Figures $15 \mathrm{~b}$ and 15d. Remarkable changes in the slope of SWCCs can be observed for the variations in the $s_{\text {opt }}$, for the KLC in Figure 15a. However, this is not the case for the TLC in Figure 15c where SWCCs are approximately parallel in the transition zone. This is due to the differences in the $x_{H}$ ranges for the KLC and TLC. The $x_{H}$ varies between 1.39 and 5.89 with the $s_{\text {opt }}$ for the KLC, over which $n$ and $m$ change drastically, while the $x_{H}$ varies between 5.48 and 17.43 with the $s_{\text {opt }}$ for the TLC, over which $n$ and $m$ changes are less significant (see Figure 13b). Such differences in the SWCCs result in pronounced variations in the predicted $M_{\text {Rrep }}-w$ relationships for the KLC but only contribute to minor variations for the TLC as shown in Figures $15 \mathrm{~b}$ and $15 \mathrm{~d}$.

\section{SUMMARY AND CONCLUSIONS}


This paper presents integrated approaches for predicting the SWCC and $M_{R}$ - moisture content relationships of compacted fine-grained subgrade soils that are required in mechanistic pavement design methods. These approaches use only measurements at saturated condition (i.e. $w_{\text {sat }}$ and $M_{\text {Rsat }}$ ) and optimum moisture content condition (i.e. $M_{\text {Ropt }}, s_{\text {opt }}$ and $S_{\text {ropt }}$ or $w_{\text {opt }}$ ) for prediction, which are similar to the information needed by the empirical approaches currently used in the MEPDG with only two additional measurements $M_{R s a t}$ and $s_{\text {opt }}$. Experimental investigations were performed using stress controlled cyclic loading tests and contact filter paper method to determine the $M_{R}$ and the SWCC after the cyclic loading tests for five compacted subgrade soils collected from different regions of Ontario province in Canada. Experimental results were predicted using the introduced approaches as well as the empirical approaches currently used in the MEPDG.

Experimental results suggest that (i) the water retention capacity and the sensitivity of the $M_{R}$ to the $w$ for the tested soils increase with soils' plasticity index and clay content, and (ii) the $M_{R}-w$ and $M_{R}$ - external stress relationships are coupled. The integrated approaches reasonably predict the SWCC and $M_{R}$ for all soils and show improved reliability compared to the empirical methods currently advocated by the MPEDG. However, caution and engineering judgement are suggested for the $M_{R}$ on the dry side of the $w_{\text {opt }}$ as over prediction is possible. Sensitivity analysis of the integrated approaches to the SWCC and $s_{\text {opt }}$ that was undertaken highlighted that the predicted $M_{R}-w$ relationships are sensitive to the slope of the SWCC. The slope of the predicted SWCC using the measurement-based approaches is sensitive to $s_{\text {opt }}$ changes at lower suction level (lower $x_{Z}$ or $x_{H}$ ) when using the extended Zapata (1999) and Houston et al. (2006) approaches but is sensitive to $s_{\text {opt }}$ changes at higher suction level (lower $x_{C}$ ) when using the Chin et al. (2010) 
approach. For these situations, uncertainties in the measurement of $s_{\text {opt }}$ pose significant influence on the predicted $M_{R}-w$ relationships.

Experimental investigations summarized in this paper provide useful data for Ontario regional subgrade soils, which can also be used as reference for other similar soils. The illustrated integrated approaches are simple yet reliable for predicting the hydraulic and resilient behavior of compacted pavement subgrade soils and for facilitating the implementation of the mechanistic pavement design methods.

\section{ACKNOWLEDGEMENT}

Authors gratefully acknowledge the funding received from the Natural Sciences and Engineering Research Council of Canada (NSERC) and the Ministry of Transportation of Ontario (MTO), Canada which supported this study. Opinions presented in this study are essentially of the authors and may not necessarily reflect the views and policies of the NSERC and MTO. The second author appreciates the "High-End Foreign Experts Recruitment Program" sponsored by the State Administration of Foreign Experts Affairs, P. R. China and the Wuhan University.

\section{REFERENCES}

AASHTO 2003. Designation T307-99: Determining the Resilient Modulus of Soils and Aggregate Materials. American Association of State Highway and Transportation Officials. Washington, D.C.

AASHTO 2008. Designation M-145: Classification of Soil and Soil-Aggregate Mixtures for Highway Construction. American Association of State Highway and Transportation Officials. Washington, D.C. 
Abu-Farsakh, M. Y., Mehrotra, A., Mohammad, L., and Gaspard, K. 2015. "Incorporating the effect of moisture variation on resilient modulus for unsaturated fine-grained subgrade soils." Transportation Research Record, 2510, Transportation Research Board, Washington, D. C., 44-53.

ARA, Inc., ERES Consultants Division 2004. Guide for Mechanistic - Empirical Design of New and Rehabilitated Pavement Structures. Final report, NCHRP Project 1-37A. Transportation Research Board, Washington, D.C.

ASTM 2007. Designation: D422-63: Standard Test Method for Particle-Size Analysis of Soils. American Society for Testing and Materials. West Conshohocken, PA.

ASTM 2009. Designation: D6913-04: Standard Test Methods for Particle-Size Distribution (Gradation) of Soils Using Sieve Analysis. American Society for Testing and Materials. West Conshohocken, PA.

ASTM 2010. Designation: D5298-10: Standard Test Method for Measurement of Soil Potential (Suction) Using Filter Paper. American Society for Testing and Materials. West Conshohocken, PA.

ASTM 2011. Designation: D2487-11: Standard Practice for Classification of Soils for Engineering Purposes (Unified Soil Classification System). American Society for Testing and Materials. West Conshohocken, PA.

ASTM 2012. Designation: D698-12: Standard Test Methods for Laboratory Compaction Characteristics of Soil Using Standard Effort $\left(12400 \mathrm{ft}-\mathrm{lbf} / \mathrm{ft} \mathrm{t}^{3}\left(600 \mathrm{kN}-\mathrm{m} / \mathrm{m}^{3}\right)\right)$. American Society for Testing and Materials. West Conshohocken, PA.

Aubertin, M., Mbonimpa, M., Bussière, B., and Chapuis, R. P. 2003. "A model to predict the water retention curve from basic geotechnical properties." Canadian Geotechnical Journal, 40(6): 1104-1122.

Azam, A. M., Cameron, D. A., and Rahman, M. M. 2013. "Model for prediction of resilient modulus incorporating matric suction for recycled unbound granular materials." Canadian Geotechnical Journal, 50(11): 1143-1158.

Bilodeau, J. P., and Doré, G. 2012. "Water sensitivity of resilient modulus of compacted unbound granular materials used as pavement base." International Journal of Pavement Engineering, 13(5): 459-471.

Caicedo, B., Coronado, O., Fleureau, J. M., and Correia, A. G. 2009. "Resilient behaviour of non standard unbound granular materials." Road Materials and Pavement Design, 10(2): 287312.

Cary, C., and Zapata, C. 2010. "Enhanced model for resilient response of soils resulting from seasonal changes as implemented in mechanistic-empirical pavement design guide." Transportation Research Record 2170, Transportation Research Board, Washington, D. C., 
$36-44$.

Cary, C. E. and Zapata, C. E. 2011. "Resilient modulus for unsaturated unbound materials." Road Materials and Pavement Design, 12(3): 615-638.

Catana, M. C., Vanapalli, S. K., and Garga, V. K. 2006. "The water retention characteristics of compacted clays.” In Proceedings of the Unsaturated Soils 2006, 1348-1359.

Chin, K. B., Leong, E. C., and Rahardjo, H. 2010. "A simplified method to estimate the soilwater characteristic curve.” Canadian Geotechnical Journal, 47(12): 1382-1400.

Coronado, O., Caicedo, B., Taibi, S., Correia, A. G., Souli, H., and Fleureau, J. M. 2016. "Effect of water content on the resilient behavior of non standard unbound granular materials." Transportation Geotechnics, 7: 29-39.

Doré, G., and Zubeck, H. 2008. Cold Regions Pavement Engineering. McGraw-Hill, New York

Drumm, E. C., Reeves, J. S., Madgett, M. R., and Trolinger, W. D. 1997. "Subgrade resilient modulus correction for saturation effects." Journal of Geotechnical and Geoenvironmental Engineering, 123(7): 663-670.

Fredlund, D. G. 2000. “The 1999 RM Hardy Lecture: The implementation of unsaturated soil mechanics into geotechnical engineering." Canadian Geotechnical Journal, 37(5): 963-986.

Fredlund, D. G. 2006. "Unsaturated soil mechanics in engineering practice." Journal of Geotechnical and Geoenvironmental Engineering, 132(3): 286-321.

Fredlund, D. G., and Xing, A. 1994. "Equations for the soil-water characteristic curve." Canadian Geotechnical Journal, 31(4): 521-532.

Fredlund, M. D., Wilson, G. W., and Fredlund, D. G. 2002. "Use of the grain-size distribution for estimation of the soil-water characteristic curve." Canadian Geotechnical Journal, 39(5): 1103-1117.

Gallipoli, D., Bruno, A. W., D'onza, F., and Mancuso, C. 2015. “A bounding surface hysteretic water retention model for deformable soils." Géotechnique, 65(10): 793-804.

Gu, F., Sahin, H., Luo, X., Luo, R., and Lytton, R. L. 2014. "Estimation of resilient modulus of unbound aggregates using performance-related base course properties." Journal of Materials in Civil Engineering. DOI: 10.1061/(ASCE)MT.1943-5533.0001147.

Han, Z., and Vanapalli, S. K. 2015. "Model for predicting the resilient modulus of unsaturated subgrade soil using the soil-water characteristic curve." Canadian Geotechnical Journal, 52(10): 1605-1619.

Han, Z., and Vanapalli, S. K. 2016a. "State-of-the-Art: Prediction of resilient modulus of unsaturated subgrade soils." International Journal of Geomechanics. DOI: 
10.1061/(ASCE)GM.1943-5622.0000631.

Han, Z., and Vanapalli, S. K. 2016b. "Stiffness and shear strength of unsaturated soils in relation to soil-water characteristic curve." Géotechnique. DOI: 10.1680/geot./15-P-104.

Houston, W. N., Dye, H. B., Zapata, C. E., Perera, Y. Y., and Harraz, A. 2006. "Determination of SWCC using one point suction measurement and standard curves." In Proceedings of the Unsaturated Soils 2006, 1482-1493.

Houston, S. L. 2014. "Characterization of unsaturated soils: The importance of response to wetting." In Proceedings of the ASCE Geo-Congress 2014 Conference, 77-96.

Hoyos, L. R., Suescún-Florez, E. A., and Puppala, A. J. 2015. "Stiffness of intermediate unsaturated soil from simultaneous suction-controlled resonant column and bender element testing." Engineering Geology, 188(7): 10-28.

Hu, R., Chen, Y. F., Liu, H. H., and Zhou, C. B. 2013. “A water retention curve and unsaturated hydraulic conductivity model for deformable soils: consideration of the change in pore-size distribution." Géotechnique, 63(16): 1389-1405.

Huang, Y. H. 2004. Pavement Analysis and Design (Second Edition). Prentice Hall: New Jercey.

Khoury, C. N., Brooks, R., Boeni, S. Y., and Yada, D. 2013. "Variation of resilient modulus, strength, and modulus of elasticity of stabilized soils with postcompaction moisture contents." Journal of Materials in Civil Engineering, 25(2): 160-166.

Khoury, N. N., and Zaman, M. M. 2004. "Correlation between resilient modulus, moisture variation, and soil suction for subgrade soils." Transportation Research Record, 1874, Transportation Research Board, Washington, D.C., 99-107.

Khoury, N., Brooks, R., Boeni, S. Y., and Yada, D. 2013. "Variation of resilient modulus, strength, and modulus of elasticity of stabilized soils with postcompaction moisture contents.” Journal of Materials in Civil Engineering, 25(2): 160-166.

LeKarp, F., Isacsson, U., and Dawson, A. 2000. "State of the art. I: Resilient response of unbound aggregates.” Journal of Transportation Engineering, 126(1): 66-75.

Leong, E. C., and Rahardjo, H. 1997. "Review of soil-water characteristic curve equations." Journal of Geotechnical and Geoenvironmental Engineering, 123(12): 1106-1117.

Leong, E. C., Tripathy, S., and Rahardjo, H. 2004. "A Modified pressure plate apparatus." Geotechnical Testing Journal, 27(3): 322-331.

Li, D., and Selig, E. T. 1994. "Resilient modulus for fine-grained subgrade soils." Journal of Geotechnical Engineering, 120(6): 939-957.

Li, Q., Ling, X., and Sheng, D. 2015. "Elasto-plastic behaviour of frozen soil subjected to long- 
term low-level repeated loading, Part I: Experimental investigation." Cold Regions Science and Technology, 125: 138-151. 
Li, Z. Y., Dong, C., Zou, J. R., and Zou, W. L. 2015. "Research on experiment and prediction model of dynamic resilient modulus of laterite soil in Southern Hunan." Rock and Soil Mechanics, 36(7): 1840-1846.

Malla, R. B., and Joshi, S. 2008. "Subgrade resilient modulus prediction models for coarse and fine-grained soils based on long-term pavement performance data." International Journal Pavement Engineering, 9(6): 431-444.

Ng, C. W. W., and Pang, Y. W. 2000. "Influence of stress state on soil-water characteristics and slope stability." Journal of Geotechnical and Geoenvironmental Engineering, 126(2): 157166.

Ng, C. W. W., and Zhou, C. 2014. "Cyclic behaviour of an unsaturated silt at various suctions and temperatures." Géotechnique, 64(9): 709-720.

Ng, C. W. W., Zhou, C., Yuan, Q., and Xu, J. 2013. "Resilient modulus of unsaturated subgrade soil: experimental and theoretical investigations." Canadian Geotechnical Journal, 50(2): 223-232.

Nokkaew, K., Tinjum, J. M., Likos, W. J., and Edil, T. B. 2014. "Effect of matric suction on resilient modulus for compacted recycled base course in postcompaction state." Transportation Research Record 2433, Transportation Research Board, Washington, D.C., 68-78.

Nuth, M., and Laloui, L. 2008. "Advances in modelling hysteretic water retention curve in deformable soils." Computers and Geotechnics, 35(6): 835-844.

Perera, Y. Y., Zapata, C. E., Houston, W. N., and Houston, S. L. 2005. "Prediction of the soilwater characteristic curve based on grain-size-distribution and index properties." Geotechnical Special Publication 130, 49-60.

Power, K. C., and Vanapalli, S. K. 2010. "Modified null pressure plate apparatus for measurement of matric suction." Geotechnical Testing Journal, 33(4): 335-341.

Power, K. C., Vanapalli, S. K., and Garga, V. 2008. "A revised contact filter paper method." Geotechnical Testing Journal, 31(6): 461-469.

Qi, S., and Vanapalli, S. K. 2015. "Hydro-mechanical coupling effect on surficial layer stability of unsaturated expansive soil slopes." Computers and Geotechnics, 70: 68-82.

Rahimi, A., and Rahardjo, H. 2016. "New approach to improve soil-water characteristic curve to reduce variation in estimation of unsaturated permeability function." Canadian Geotechnical Journal, 53(4): 717-725.

Ridley, A. M., Dineen, K., Burland, J. B., and Vaughan, P. R. 2003. "Soil matrix suction: some examples of its measurement and application in geotechnical engineering." Géotechnique, 53(2): 241-253. 
Romero, E., Gens, A., and Lloret, A. 1999. "Water permeability, water retention and microstructure of unsaturated compacted Boom clay." Engineering Geology, 54(1): 117127.

Sahin, H., Gu, F., and Lytton, R. L. 2014. "Development of soil-water characteristic curve for flexible base materials using the methylene blue test." Journal of Materials in Civil Engineering, 27(5), 04014175.

Salour, F., Erlingsson, S., and Zapata, C. E. 2014. "Modelling resilient modulus seasonal variation of silty sand subgrade soils with matric suction control." Canadian Geotechnical Journal, 51(12): 1413-1422.

Sawangsuriya, A., Edil, T. B., and Benson, C. H. 2009. "Effect of suction on resilient modulus of compacted fine-grained subgrade soils." Transportation Research Record, 2101, Transportation Research Board, Washington, D. C., 82-87.

Sheng, D. 2011. "Review of fundamental principles in modelling unsaturated soil behaviour." Computers and Geotechnics, 38(6): 757-776.

Sillers, W. S., and Fredlund, D. G. 2001. "Statistical assessment of soil-water characteristic curve models for geotechnical engineering." Canadian Geotechnical Journal, 38(6): 12971313.

Simms, P. H., and Yanful, E. K. 2001. "Measurement and estimation of pore shrinkage and pore distribution in a clayey till during soil-water characteristic curve tests." Canadian Geotechnical Journal, 38(4): 741-754.

Sivakumar, V., Kodikara, J., O'Hagan, R., Hughes, D., Cairns, P., and McKinley, J. D. 2013. "Effects of confining pressure and water content on performance of unsaturated compacted clay under repeated loading." Géotechnique, 63(8): 628-640.

Tarantino, A., Gallipoli, D., Augarde, C. E., De Gennaro, V., Gomez, R., Laloui, L., and Péron, H. 2011. "Benchmark of experimental techniques for measuring and controlling suction." Géotechnique, 61(4): 303-312.

Tian, P., Zaman, M. M., and Laguros, J. G. 1998. "Gradation and moisture effects on resilient moduli of aggregate bases." Transportation Research Record, 1619, Transportation Research Board, Washington, D. C., 75-84.

Uzan, J. 1998. "Characterization of clayey subgrade materials for mechanistic design of flexible pavements." Transportation Research Record, 1629, Transportation Research Board, Washington, D. C., 189-196.

van Genuchten, M. T. 1980. "A closed-form equation for predicting the hydraulic conductivity of unsaturated soils." Soil Science Society of America Journal, 44(5): 892-898. 
Vanapalli, S. K., and Oh, W. T. 2011. "Simple techniques for the estimation of suction in compacted soils in the range of 0 to 60,000 kPa." Geotechnical Testing Journal, 34(6): 765774.

Vanapalli, S. K., Fredlund, D. G., and Pufahl, D. E. 1999. "Influence of soil structure and stress history on the soil-water characteristics of a compacted till." Géotechnique, 49(2): 143-159.

Yang, S. R., Huang, W. H., and Tai, Y. T. 2005. "Variation of resilient modulus with soil suction for compacted subgrade soils." Transportation Research Record, 1913, Transportation Research Board, Washington, D. C., 99-106.

Zapata, C. E. 1999. Uncertainty in Soil-Water-Characteristic Curve and Impacts on Unsaturated Shear Strength Predictions. Ph.D. Thesis, Arizona State University.

Zapata, C. E., Houston, W. N., Houston, S. L., and Walsh, K. D. 2000. "Soil-water characteristic curve variability." ASCE Geotechnical Special Publication 99, 84-124.

Zapata, C. E., Andrei, D., Witczak, M. W., and Houston, W. N. 2007. "Incorporation of environmental effects in pavement design." Road Materials and Pavement Design, 8(4): 667-693.

Zapata, C. E., and Houston, W. N. 2008. Calibration and Validation of the Enhanced Integrated Climatic Model for Pavement Design. NCHRP Report 602, National Cooperative Highway Research Program, Transportation Research Board of the National Academies.

Zhai, Q., and Rahardjo, H. 2013. "Quantification of uncertainties in soil-water characteristic curve associated with fitting parameters.” Engineering Geology, 163: 144-152.

Zou, W. L., Zhang, J. F., Li, Y. L., Vanapalli, S. K., Tu, H. Y., and Zhang, J. 2015. "Comparisons between the measured and predicted resilient modulus of subgrade red clay using a SWCC based model." In Proceedings of the $6^{\text {th }}$ Asia-Pacific Conference on Unsaturated Soils, Guilin, China, 743-748. 


\section{List of Figures}

Figure 1. SWCC families used by (a) Houston et al. (2005), (b) Extended Zapata (1999) and (c) Chin et al. (2010), and (d) comparison between predicted SWCCs

Figure 2. Steps for predicting the SWCC and the $M_{R}$ - moisture content relationship

Figure 3. Locations of the five subgrade soils

Figure 4. Gradation curves of the five subgrade soils

Figure 5. Compaction curves of the five subgrade soils

Figure 6. Measured, fitted and predicted (using empirical approaches) SWCCs for (a) KLC, (b) SLC, (c) TSC, (d) TLC and (e) OLC

Figure 7. Measured, fitted and predicted (using measurement-based approaches) SWCCs for (a) KLC, (b) SLC, (c) TSC, (d) TLC and (e) OLC

Figure 8 . Sensitivity of $M_{\text {Rrep }}$ to $w$ for the five subgrade soils

Figure 9. Measured and predicted variation of $M_{\text {Rrep }}$ with $w$ for (a) KLC, (b) SLC, (c) TSC, (d) TLC and (e) OLC

Figure 10. Measured and predicted $M_{R}-\sigma_{d}-w$ relationships for (a) KLC, (b) SLC, (c) TSC, (d) TLC and (e) OLC at $\sigma_{c}$ of $27.6 \mathrm{kPa}$

Figure 11. Measured and predicted $M_{R}-\sigma_{d}-w$ relationships for SLC using (a) SWCC fitted by Fredlund and Xing (1994) and SWCC predicted by (b) extended Zapata (1999), (c) Houston et al. (2006) and (d) Chin et al. (2010) and (e) MEPDG method at $\sigma_{c}$ of 27.6 $\mathrm{kPa}$

Figure 12. Comparisons between the measured and predicted $M_{R}$ of (a) KLC, (b) SLC, (c) TSC, (d) TLC and (e) OLC 
Figure 13. Variation of $a, n$ and $m$ described by (a) Zapata (1999), (b) Perera et al. (2005) and (c) Chin et al. (2010)

Figure 14. Sensitivities of predicted (a) SWCC to $a$, (b) $M_{\text {Rrep }}$ to $a$, (c) SWCC to $n$, (d) $M_{\text {Rrep }}$ to $n$, (e) SWCC to $m$ and (f) $M_{\text {Rrep }}$ to $m$ for the TLC

Figure 15. Influence of $s_{\text {opt }}$ on (a) SWCC of KLC, (b) $M_{\text {Rrep }}-w$ relationship of KLC, (c) SWCC of TLC and (d) $M_{\text {Rrep }}-w$ relationship of TLC 

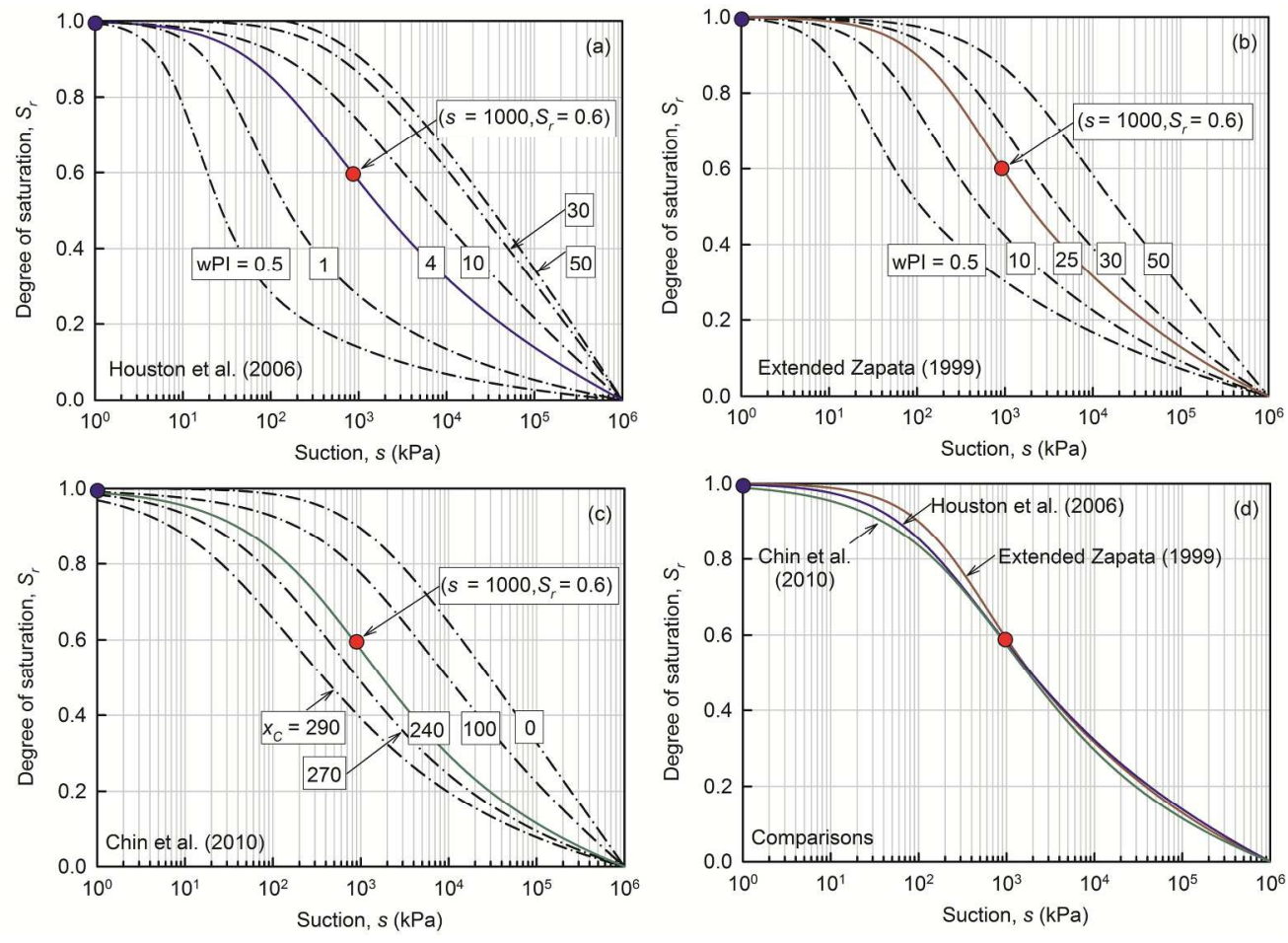

Figure 1. SWCC families used by (a) Houston et al. (2005), (b) Extended Zapata (1999) and (c) Chin et al. (2010), and (d) comparison between predicted SWCCS $220 \times 160 \mathrm{~mm}(300 \times 300 \mathrm{DPI})$ 


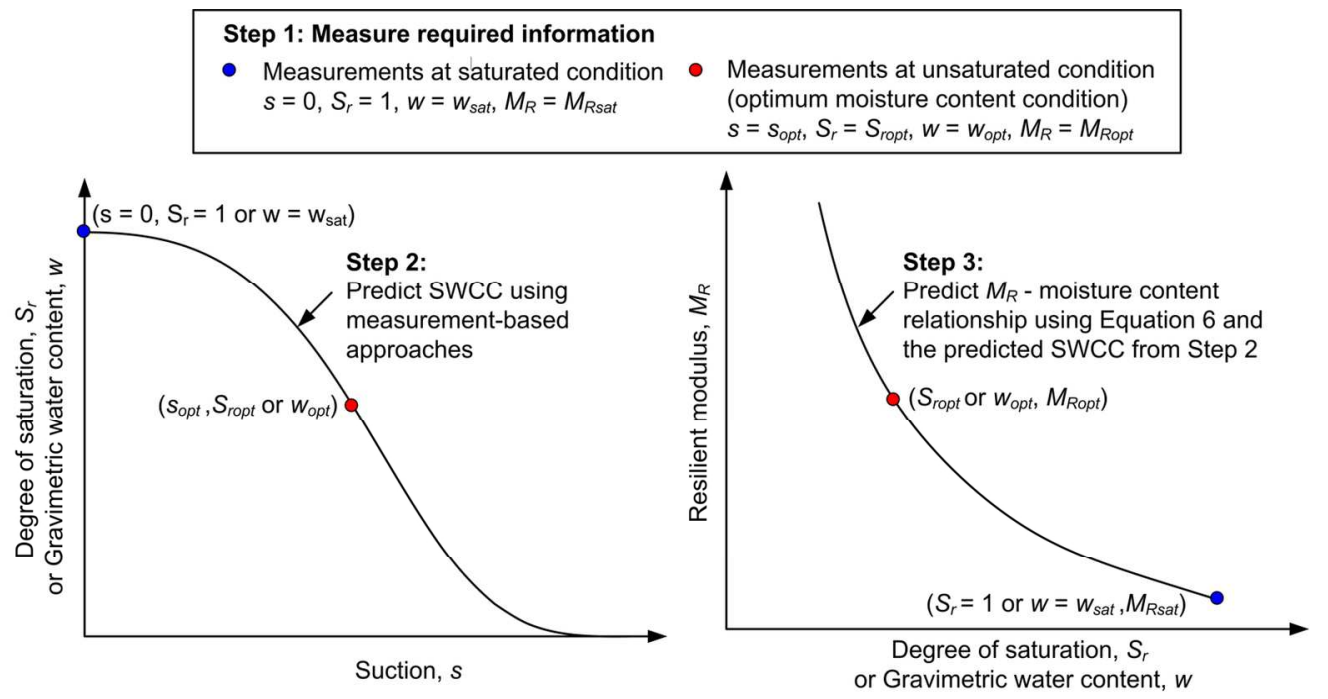

Figure 2. Steps for predicting the SWCC and the MR - moisture content relationship $138 \times 73 \mathrm{~mm}(300 \times 300 \mathrm{DPI})$ 


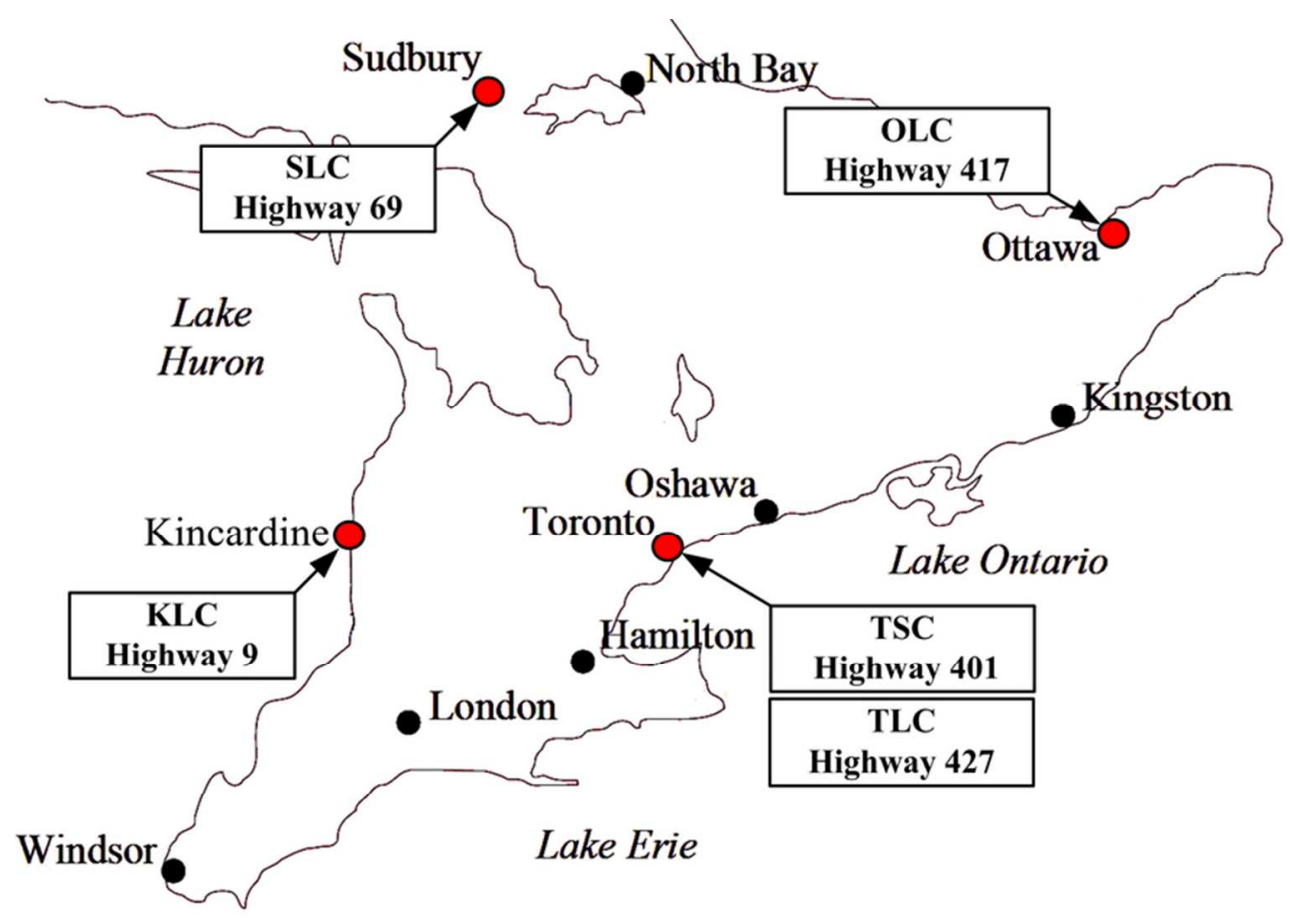

Figure 3. Locations of the five subgrade soils

$$
76 \times 52 \mathrm{~mm}(300 \times 300 \text { DPI })
$$




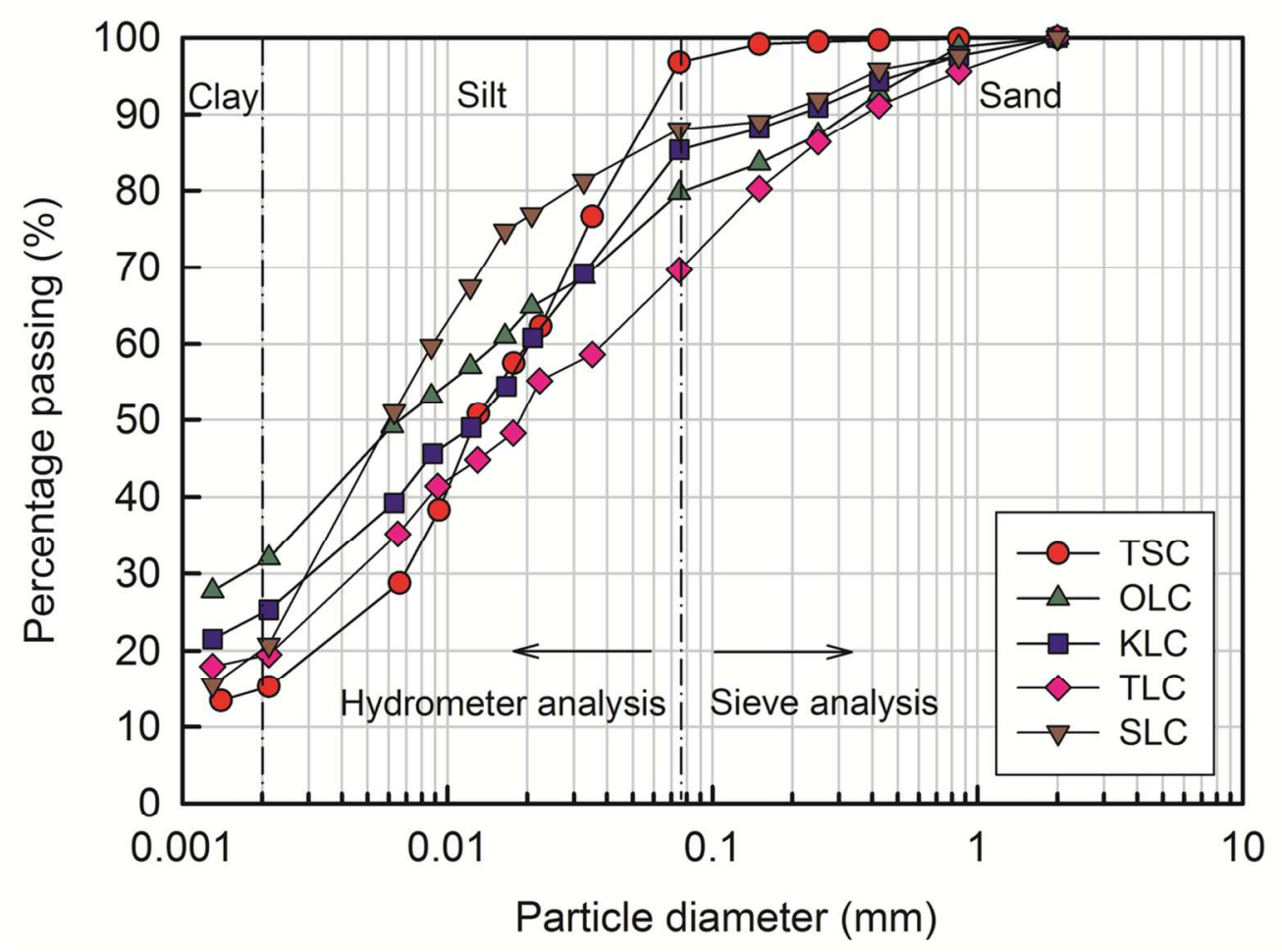

Figure 4. Gradation curves of the five subgrade soils $112 \times 83 \mathrm{~mm}(300 \times 300 \mathrm{DPI})$ 


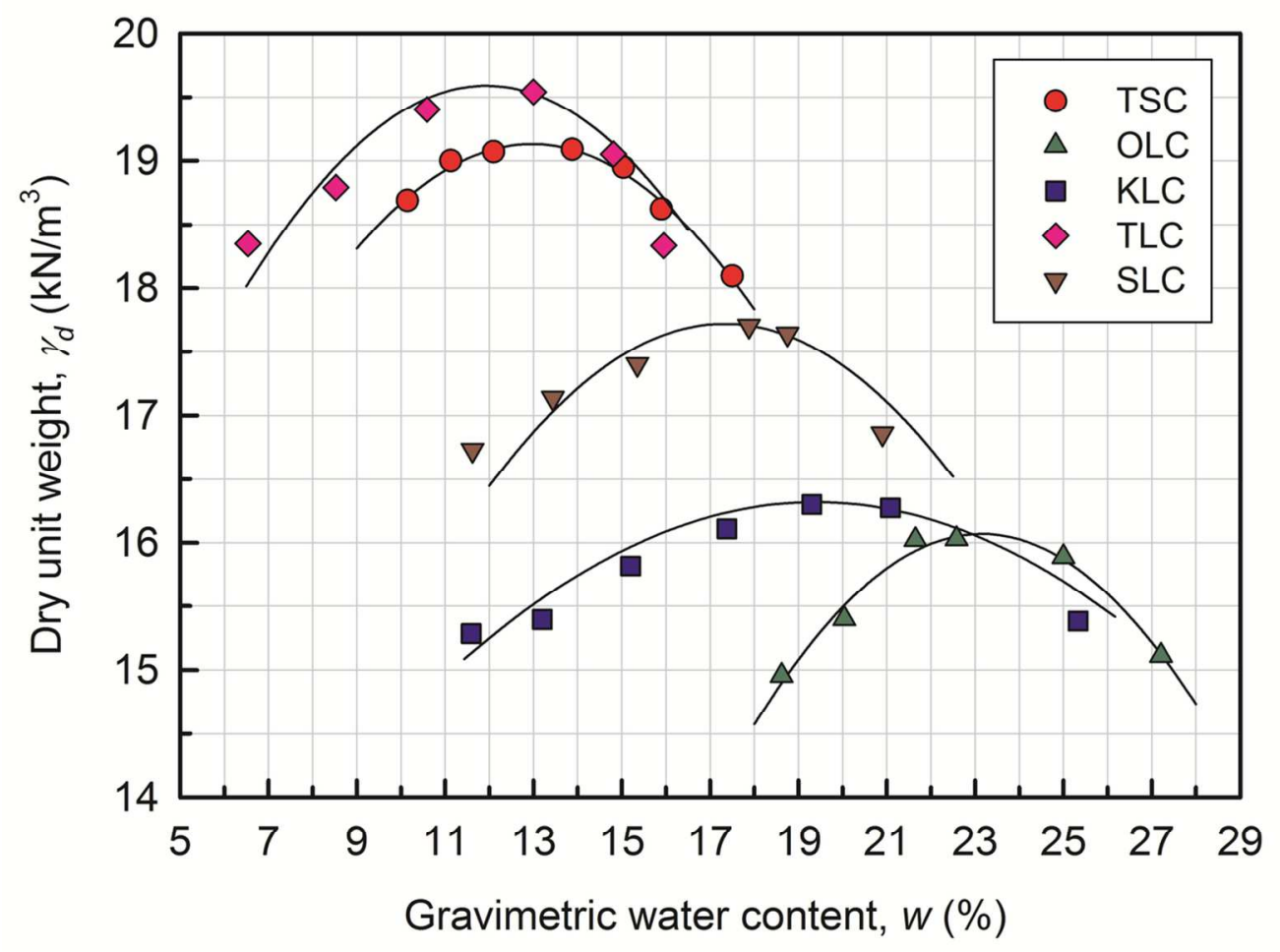

Figure 5. Compaction curves of the five subgrade soils $113 \times 85 \mathrm{~mm}(300 \times 300 \mathrm{DPI})$ 

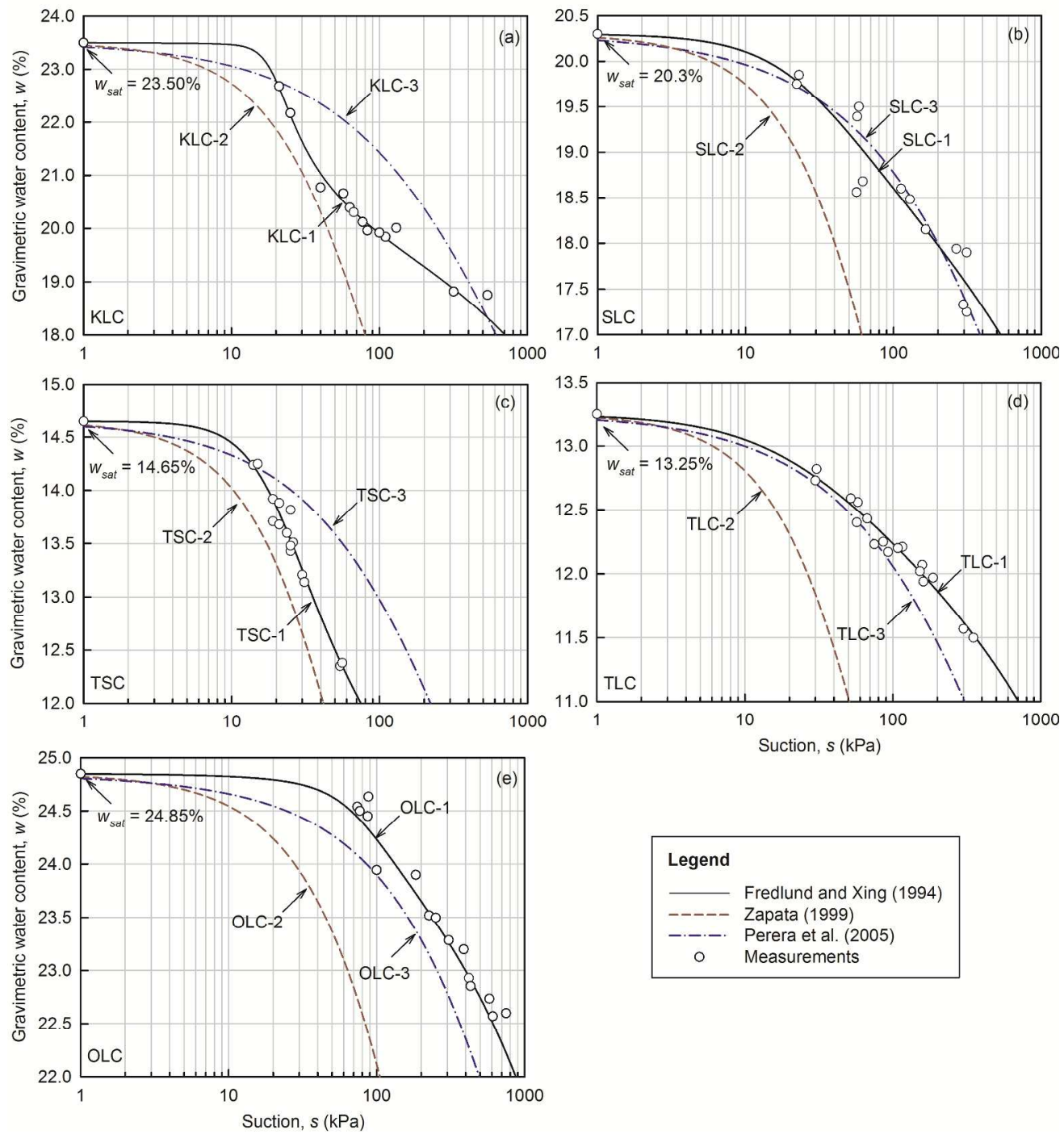

Figure 6. Measured, fitted and predicted (using empirical approaches) SWCCs for (a) KLC, (b) SLC, (c) TSC, (d) TLC and (e) OLC

$296 \times 320 \mathrm{~mm}(300 \times 300$ DPI $)$ 

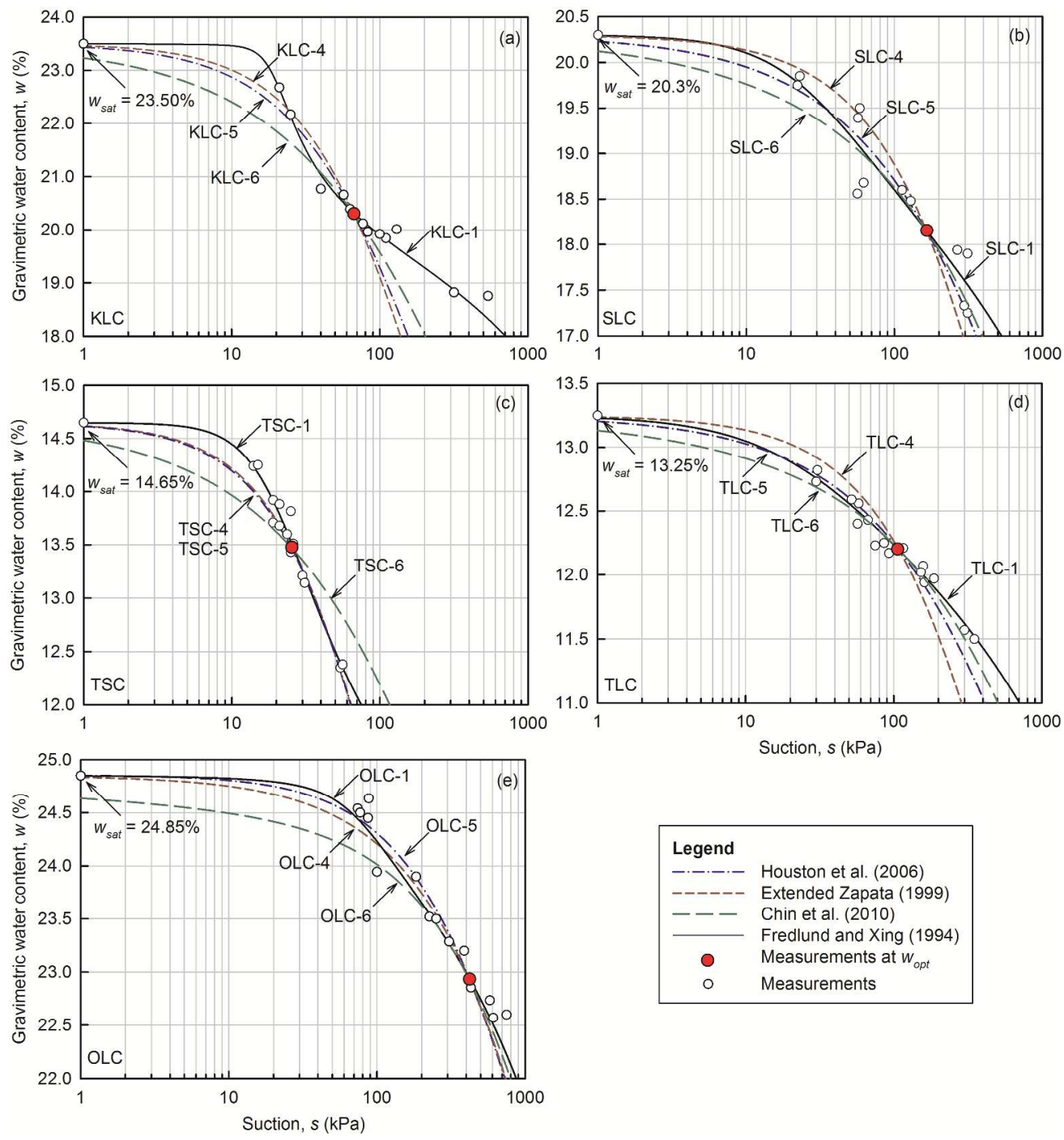

Figure 7. Measured, fitted and predicted (using measurement-based approaches) SWCCs for (a) KLC, (b) SLC, (c) TSC, (d) TLC and (e) OLC

$296 \times 317 \mathrm{~mm}(300 \times 300$ DPI $)$ 


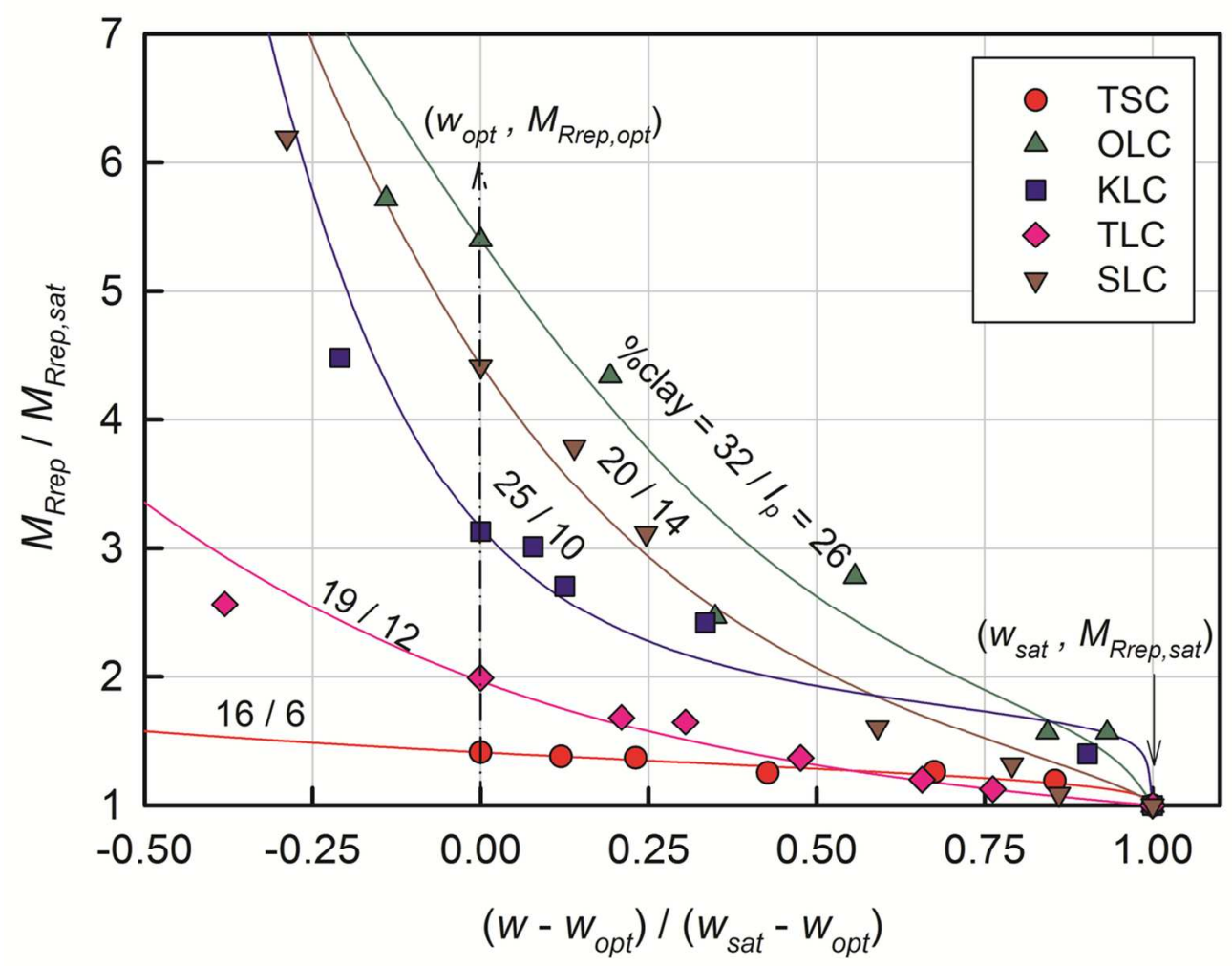

Figure 8 . Sensitivity of MRrep to $w$ for the five subgrade soils $112 \times 88 \mathrm{~mm}(300 \times 300$ DPI $)$ 

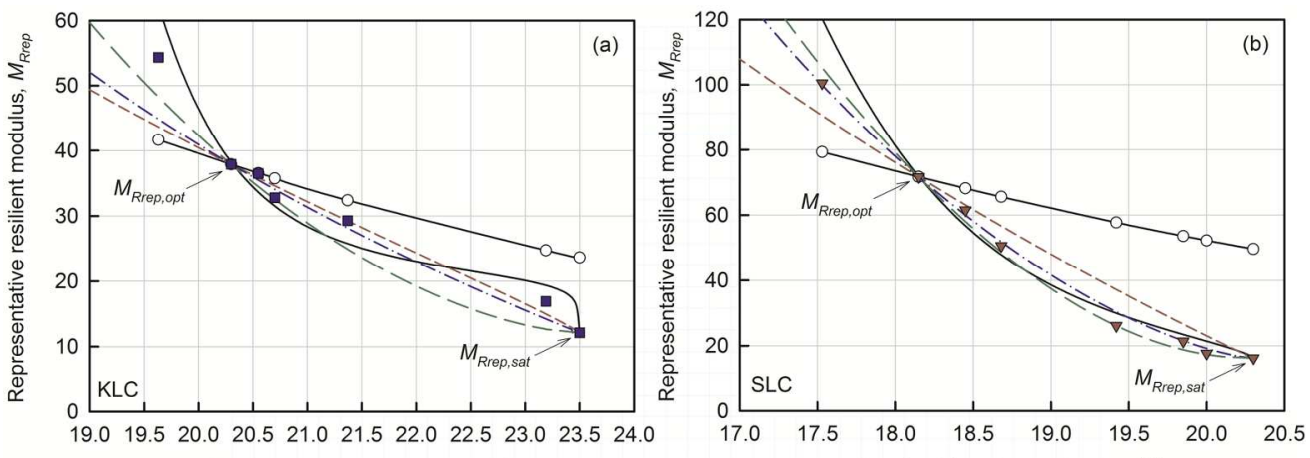

Gravimetric water content, w (\%)

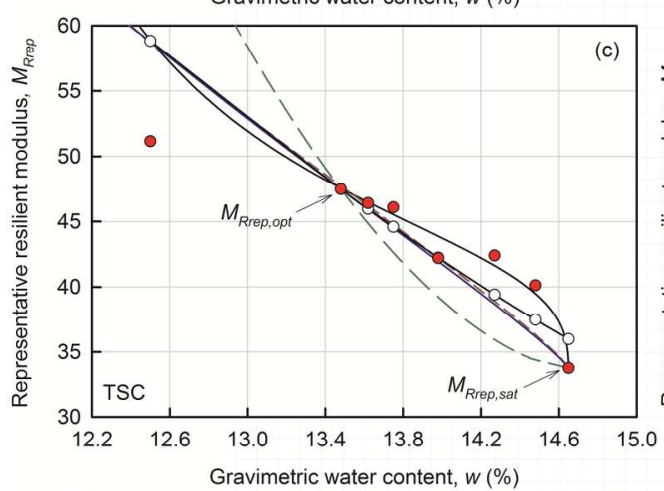

Gravimetric water content, w (\%)
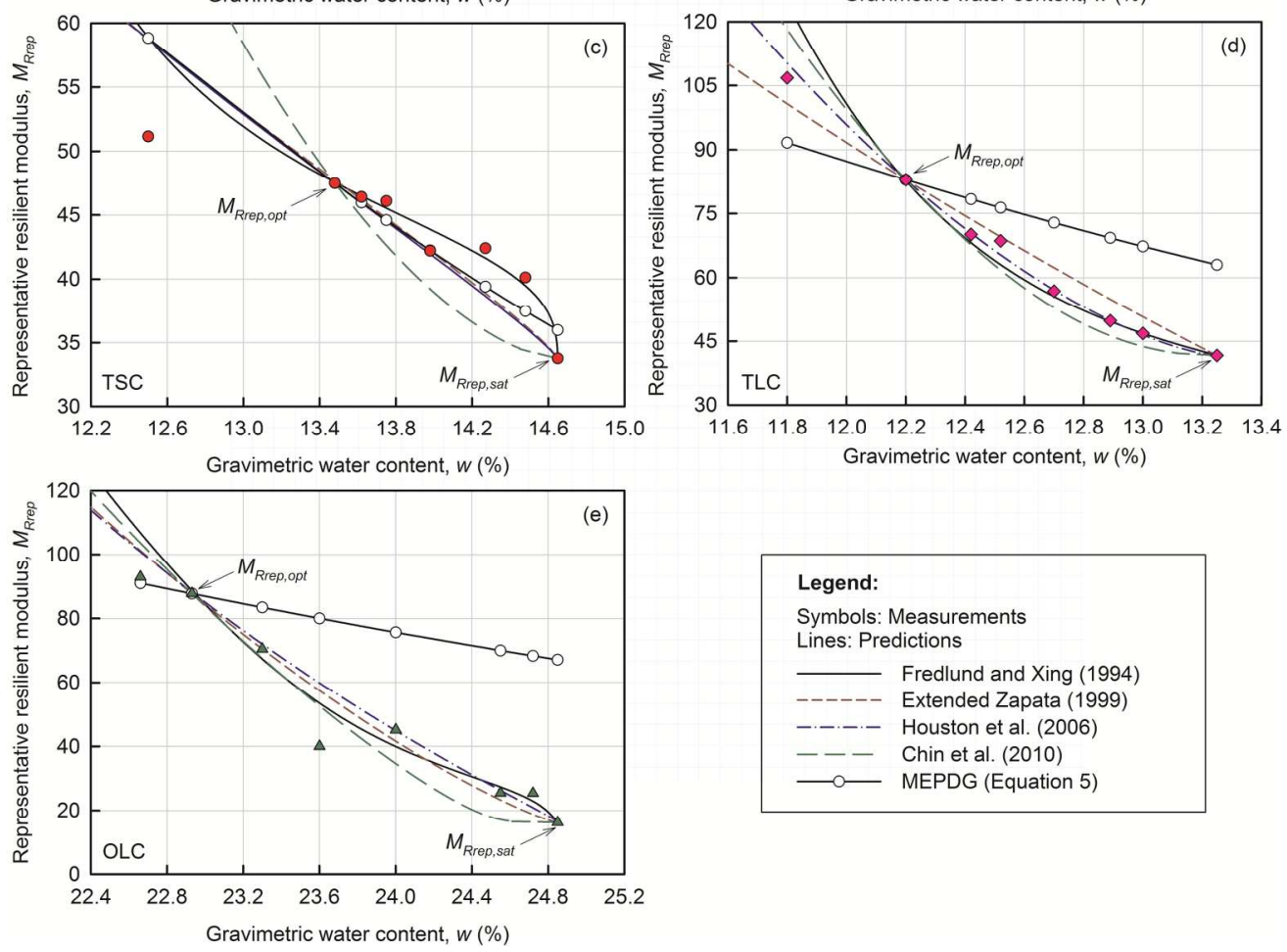

Figure 9. Measured and predicted variation of MRrep with $w$ for (a) KLC, (b) SLC, (c) TSC, (d) TLC and (e) OLC

$329 \times 364 \mathrm{~mm}(300 \times 300$ DPI $)$ 

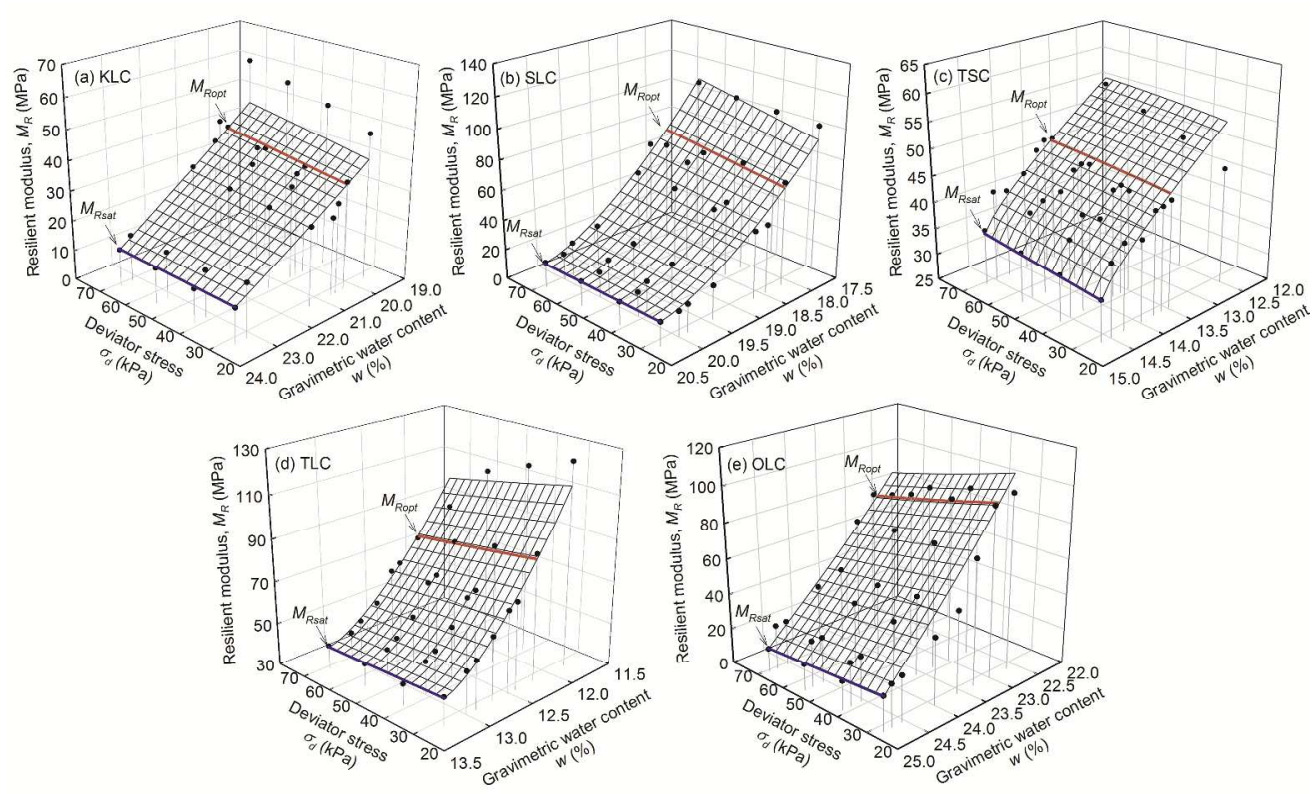

Figure 10. Measured and predicted MR - od - w relationships for (a) KLC, (b) SLC, (c) TSC, (d) TLC and (e) OLC at oc of $27.6 \mathrm{kPa}$

$387 \times 235 \mathrm{~mm}(300 \times 300 \mathrm{DPI})$ 

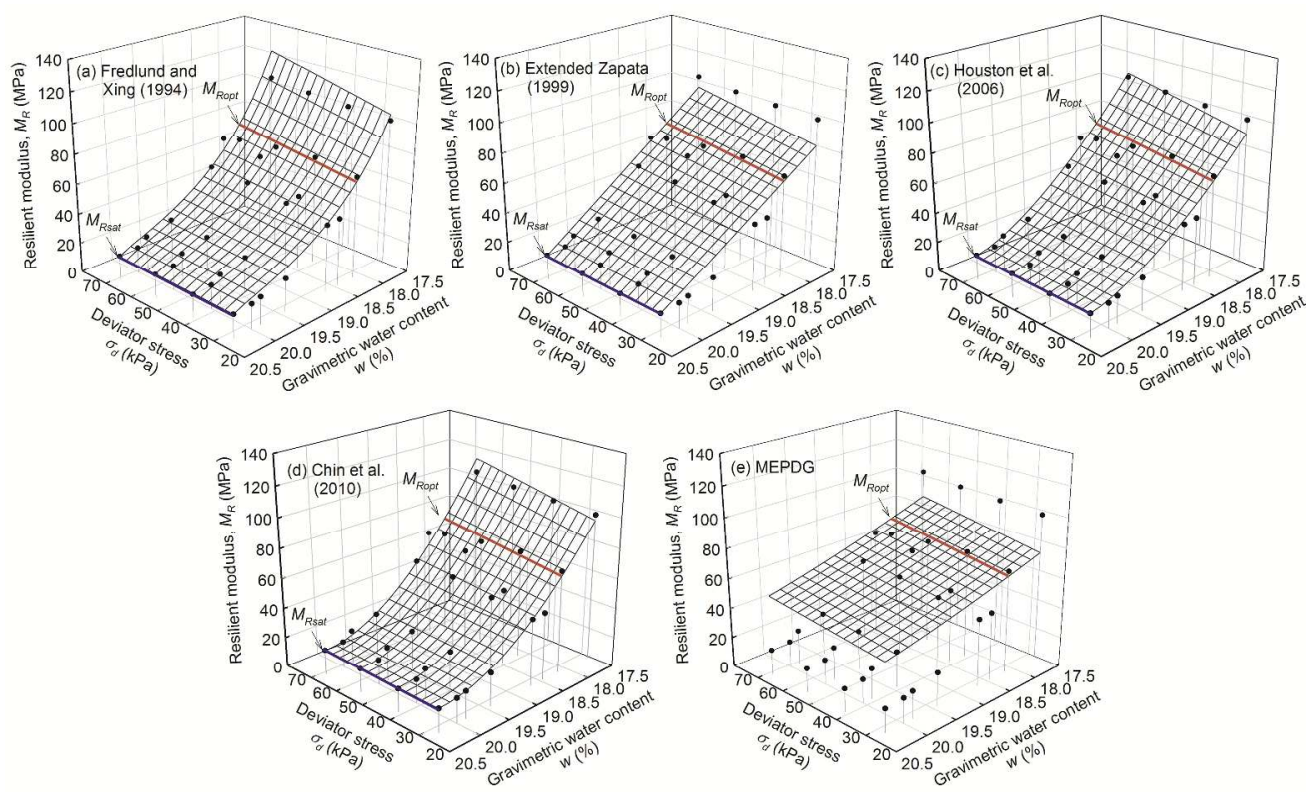

Figure 11. Measured and predicted MR - $\sigma d-w$ relationships for SLC using (a) SWCC fitted by Fredlund and Xing (1994) and SWCC predicted by (b) extended Zapata (1999), (c) Houston et al. (2006) and (d) Chin et al. (2010) and (e) MEPDG method at oc of $27.6 \mathrm{kPa}$

$391 \times 238 \mathrm{~mm}(300 \times 300 \mathrm{DPI})$ 

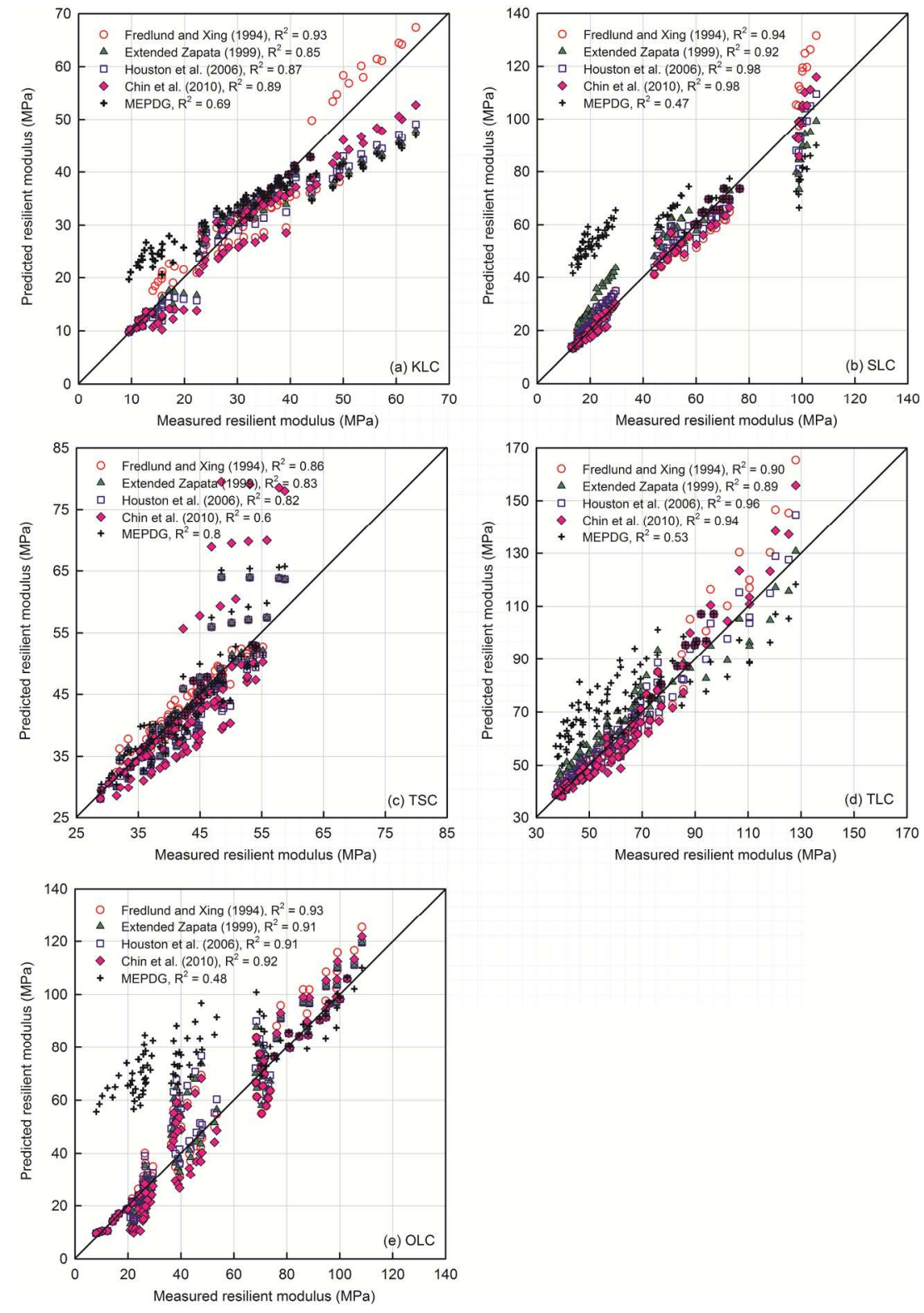

Figure 12. Comparisons between the measured and predicted MR of (a) KLC, (b) SLC, (c) TSC, (d) TLC and (e) OLC

$438 \times 629 \mathrm{~mm}(300 \times 300 \mathrm{DPI})$ 

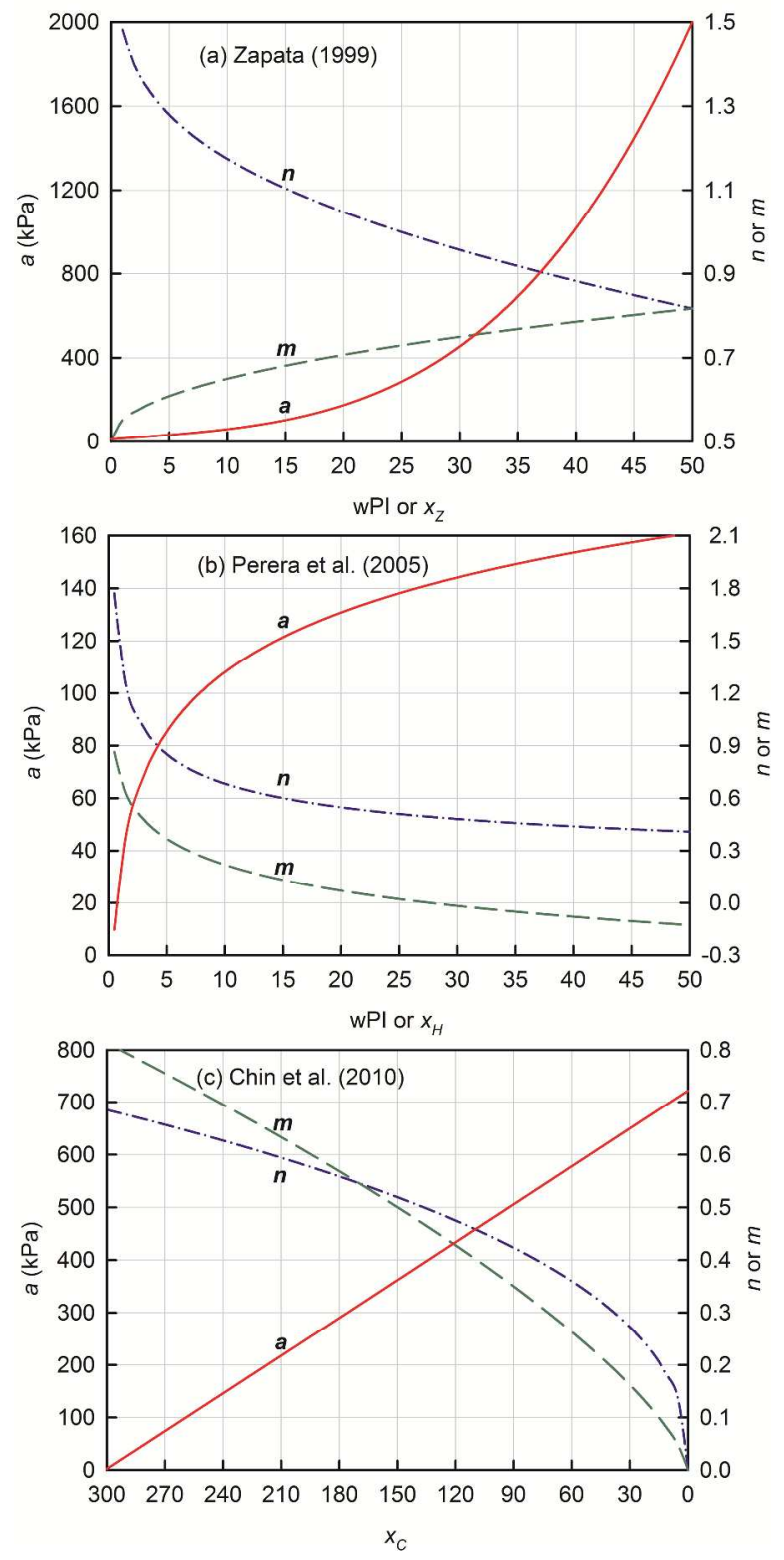

Figure 13. Variation of a, $n$ and $m$ described by (a) Zapata (1999), (b) Perera et al. (2005) and (c) Chin et al. (2010)

$335 \times 691 \mathrm{~mm}(300 \times 300$ DPI $)$ 

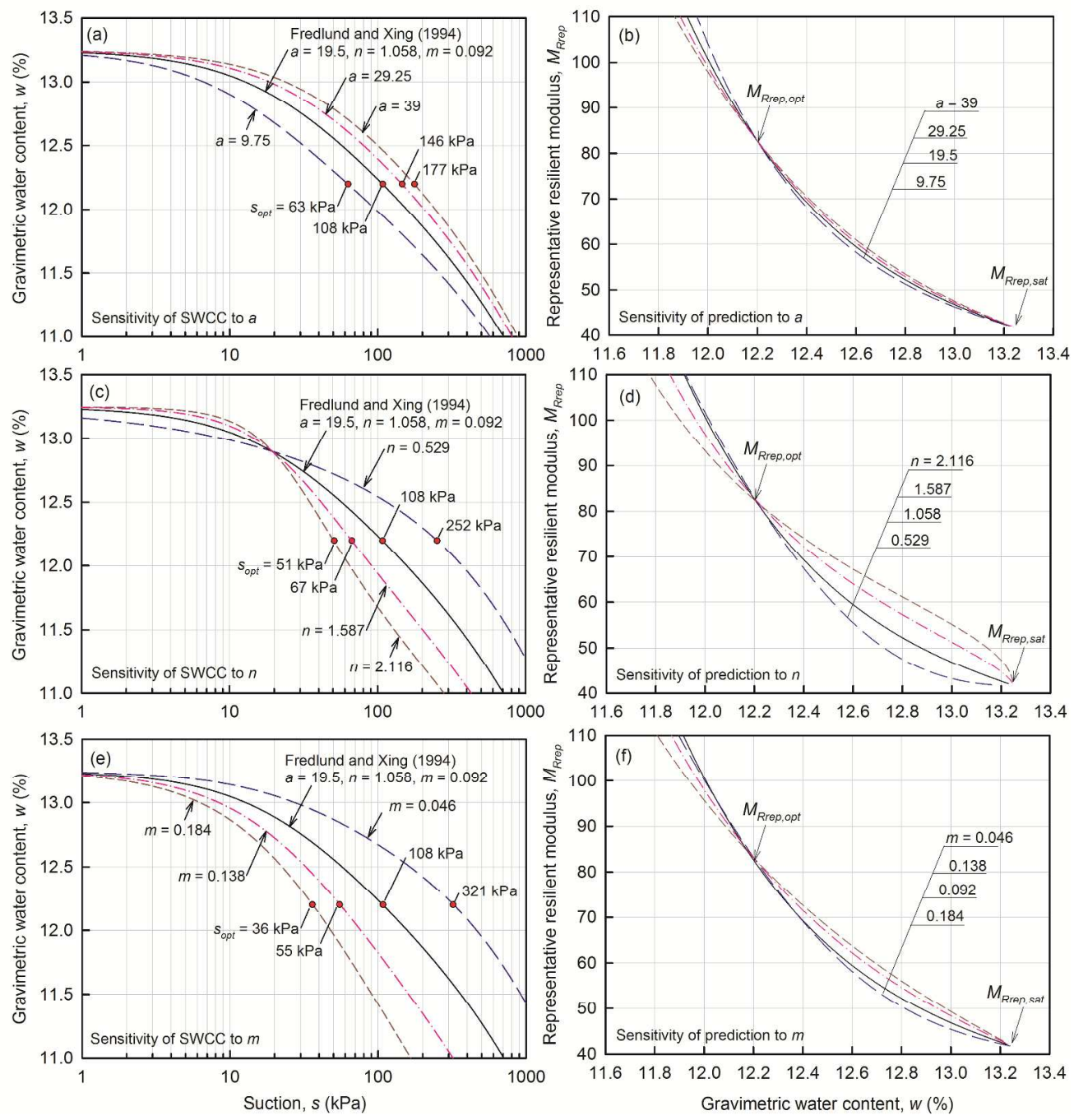

Figure 14. Sensitivities of predicted (a) SWCC to a, (b) MRrep to a, (c) SWCC to $n$, (d) MRrep to $n$, (e) SWCC to $m$ and (f) MRrep to $m$ for the TLC

$301 \times 316 \mathrm{~mm}(300 \times 300 \mathrm{DPI})$ 

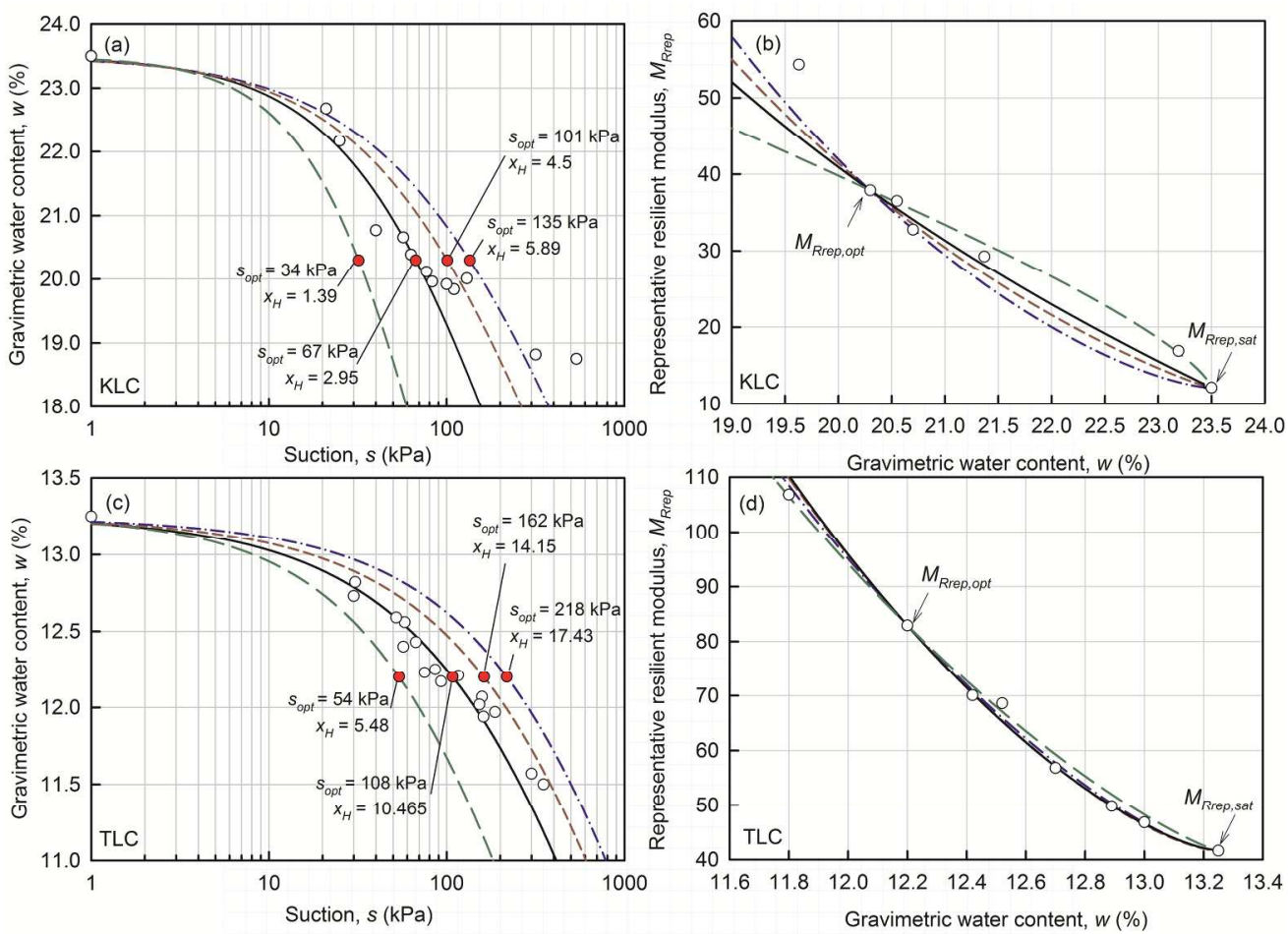

Figure 15. Influence of sopt on (a) SWCC of KLC, (b) MRrep - w relationship of KLC, (c) SWCC of TLC and (d) MRrep - w relationship of TLC

$219 \times 160 \mathrm{~mm}(300 \times 300 \mathrm{DPI})$ 
Table 1. Comparisons between the approaches used in the MEPDG and the integrated approaches introduced in this paper

\begin{tabular}{|c|c|c|c|}
\hline \multicolumn{2}{|l|}{ Details } & MEPDG approaches & Integrated approaches \\
\hline \multirow[b]{2}{*}{ SWCC } & Equation & Equation 2 & Equation 2 or 3 or 4 \\
\hline & $\begin{array}{l}\text { Required } \\
\text { information }\end{array}$ & $\begin{array}{l}\text { wPI (i.e. } I_{p} \text { and fine } \% \text { ) and } \\
*_{w_{\text {sat }}}\end{array}$ & ${ }^{*} w_{\text {sat }}, S_{\text {opt }}$ and $S_{\text {ropt }}$ or $* w_{o p t}$ \\
\hline \multirow[b]{2}{*}{$M_{R}$} & Equation & Equation 5 & Equation 6 \\
\hline & $\begin{array}{l}\text { Required } \\
\text { information }\end{array}$ & $M_{\text {Ropt }}$ and $S_{\text {ropt }}$ or $* w_{\text {opt }}$ & $\begin{array}{l}M_{\text {Ropt }}, M_{\text {Rsat }}, S_{\text {opt }} \text { and } S_{\text {ropt }} \text { or } \\
* w_{\text {opt }}\end{array}$ \\
\hline
\end{tabular}


Table 2. Physical properties of five Ontario subgrade soils

\begin{tabular}{|c|c|c|c|c|c|}
\hline Soil ID & $\mathrm{KLC}$ & SLC & TSC & TLC & $\mathrm{OLC}$ \\
\hline$w_{L}(\%)$ & 31 & 32.5 & 19.6 & 25 & 48 \\
\hline$I_{p}$ & 10 & 14 & 6 & 12 & 26 \\
\hline$w_{\text {opt }}(\%)$ & 20.3 & 18.15 & 13.5 & 12.2 & 23.0 \\
\hline$S_{\text {ropt }}(\%)$ & 84 & 91 & 90 & 88 & 90 \\
\hline$\gamma_{\text {dmax }}\left(\mathrm{kN} / \mathrm{m}^{3}\right)$ & 16.31 & 17.70 & 19.15 & 19.62 & 16.16 \\
\hline$G_{S}$ & 2.71 & 2.74 & 2.68 & 2.69 & 2.75 \\
\hline$\%$ sand & 15 & 10 & 3 & 31 & 20 \\
\hline$\%$ silt & 60 & 70 & 81 & 50 & 48 \\
\hline$\%$ clay & 25 & 20 & 16 & 19 & 32 \\
\hline wPI & 8.50 & 10.56 & 5.82 & 8.28 & 20.8 \\
\hline AASHTO & A-4 & A-6 & A-4 & A-6 & A-6 \\
\hline USCS & $\mathrm{CL}$ & $\mathrm{CL}$ & CL-ML & $\mathrm{CL}$ & $\mathrm{CL}$ \\
\hline \multicolumn{6}{|c|}{$\begin{array}{l}\text { Note: } w_{L}=\text { liquid limit; } I_{p}=\text { plasticity index }\left(w_{L} \text { and } I_{p} \text { are determined as per ASTM }\right. \\
\text { D4318-10, ASTM 2010); } w_{\text {opt }}=\text { optimum moisture content; } \gamma_{d m a x}=\text { maximum dry } \\
\text { unit weight; } G_{s}=\text { specific gravity (determined as per ASTM D854-00, ASTM } \\
\text { 2010); USCS = Unified Soil Classification System (ASTM D2487-11, ASTM } \\
\text { 2011); AASHTO = American Association of State Highway and Transportation } \\
\text { Officials soil classification system (AASHTO M145-91, AASHTO 2008). }\end{array}$} \\
\hline
\end{tabular}


Table 3. Summary of the data for all the tested specimens of the five soils

\begin{tabular}{|c|c|c|c|c|c|c|c|}
\hline \multirow{2}{*}{ Specimens } & \multirow{2}{*}{$w(\%)$} & \multirow{2}{*}{$s(\mathrm{kPa})$} & \multicolumn{5}{|c|}{${ }^{3}$ Equation 7} \\
\hline & & & $k_{1}$ & $k_{2}$ & $k_{3}$ & $\mathrm{R}^{2}$ & $M_{\text {Rrep }}(\mathrm{MPa})$ \\
\hline${ }^{1} \mathrm{KLC}$ s1 & 23.50 & 0 & 119.9 & 0.39 & -0.47 & 0.84 & 12.12 \\
\hline KLC s2 & 23.19 & 16 & 222.3 & 0.42 & -1.89 & 0.87 & 16.91 \\
\hline KLC s3 & 21.37 & 35 & 241.9 & 0.53 & 0.23 & 0.92 & 29.29 \\
\hline KLC s4 & 20.70 & 50 & 236.7 & 0.37 & 1.10 & 0.97 & 32.79 \\
\hline KLC s5 & 20.55 & 55 & 241.7 & 0.52 & 1.33 & 0.99 & 36.49 \\
\hline${ }^{2} \mathrm{KLC}$ s6 & 20.30 & 67 & 325.1 & 0.23 & 0.44 & 0.96 & 37.9 \\
\hline KLC s7 & 19.63 & 136 & 426.4 & 0.24 & 0.87 & 0.96 & 54.33 \\
\hline${ }^{1}$ SLC s 1 & 20.30 & 0 & 155 & 0.35 & -0.23 & 0.90 & 16.24 \\
\hline SLC s2 & 20.00 & 11 & 178.4 & 0.31 & -0.46 & 0.79 & 17.66 \\
\hline SLC s3 & 19.85 & 17 & 159.6 & 0.35 & 0.95 & 0.94 & 21.34 \\
\hline SLC s4 & 19.42 & 38 & 215.8 & 0.24 & 0.61 & 0.94 & 26.11 \\
\hline SLC s5 & 18.68 & 94 & 412.4 & 0.14 & 0.82 & 0.98 & 50.6 \\
\hline SLC s6 & 18.45 & 120 & 415 & 0.09 & 1.81 & 0.74 & 61.53 \\
\hline${ }^{2} \mathrm{SLC}$ s 7 & 18.15 & 165 & 591.2 & 0.19 & 0.70 & 0.76 & 71.7 \\
\hline SLC s8 & 17.53 & 324 & 953 & 0.03 & 0.23 & 0.74 & 100.51 \\
\hline${ }^{1} \mathrm{TSC}$ s 1 & 14.65 & 0 & 321.5 & 0.31 & -0.17 & 0.97 & 33.76 \\
\hline $\mathrm{TSC} \mathrm{s} 2$ & 14.48 & 9 & 387.2 & 0.39 & -0.34 & 0.98 & 40.13 \\
\hline TSC s3 & 14.27 & 13 & 401.5 & 0.46 & -0.34 & 0.96 & 42.41 \\
\hline TSC s4 & 13.98 & 18 & 407.6 & 0.47 & -0.45 & 0.98 & 42.21 \\
\hline TSC s5 & 13.75 & 21 & 469.5 & 0.50 & -0.75 & 0.99 & 46.09 \\
\hline TSC s6 & 13.62 & 23 & 436.1 & 0.45 & -0.29 & 0.99 & 46.41 \\
\hline${ }^{2} \mathrm{TSC}$ s 7 & 13.48 & 25 & 476.4 & 0.39 & -0.53 & 0.93 & 47.49 \\
\hline TSC s8 & 12.50 & 48 & 418.1 & 0.24 & 0.67 & 0.97 & 51.16 \\
\hline${ }^{\mathrm{I}} \mathrm{TLC} \mathrm{s} 1$ & 13.25 & 0 & 459.5 & 0.20 & -0.75 & 0.82 & 41.63 \\
\hline TLC s2 & 13.00 & 9 & 652.5 & 0.46 & -2.23 & 0.95 & 46.84 \\
\hline TLC s3 & 12.89 & 16 & 627.5 & 0.43 & -1.69 & 0.97 & 49.83 \\
\hline TLC s4 & 12.70 & 33 & 705.9 & 0.43 & -1.62 & 0.95 & 56.83 \\
\hline TLC s5 & 12.52 & 54 & 817.2 & 0.49 & -1.50 & 0.98 & 68.61 \\
\hline TLC s6 & 12.42 & 68 & 765.8 & 0.25 & -0.76 & 0.93 & 70.09 \\
\hline${ }^{2}$ TLC s7 & 12.20 & 108 & 989.1 & 0.29 & -1.24 & 0.94 & 82.93 \\
\hline TLC s8 & 11.80 & 212 & 1602 & 0.20 & -2.25 & 0.92 & 106.8 \\
\hline${ }^{1} \mathrm{OLC} \mathrm{s1}$ & 24.85 & 0 & 273 & 1.20 & -4.12 & 0.96 & 16.25 \\
\hline OLC s2 & 24.72 & 41 & 267.4 & 0.40 & -0.78 & 0.94 & 25.4 \\
\hline OLC s3 & 24.55 & 68 & 247.9 & 0.21 & -0.15 & 0.89 & 25.44 \\
\hline OLC s4 & 24.00 & 147 & 533.8 & 0.39 & -1.33 & 0.97 & 45.18 \\
\hline OLC s5 & 23.60 & 219 & 469.5 & 0.22 & -1.07 & 0.67 & 40.03 \\
\hline OLC s6 & 23.30 & 290 & 720.9 & -0.07 & -0.02 & 0.80 & 70.45 \\
\hline${ }^{2} \mathrm{OLC} \mathrm{s} 7$ & 22.93 & 420 & 1170 & 0.29 & -1.79 & 0.94 & 87.73 \\
\hline OLC s8 & 22.66 & 558 & 1279 & 0.15 & -1.76 & 0.86 & 92.92 \\
\hline
\end{tabular}

Note: ${ }^{1}$ specimens at $w_{\text {sat }},{ }^{2}$ specimen at $w_{\text {opt }}$ and $s_{\text {opt }} ;{ }^{3}$ In Equation $7, \theta, \tau_{\text {oct }}$ and $M_{R}$ are in $\mathrm{kPa}$, and $p_{a}=100 \mathrm{kPa}$ when determining model parameters. 
Table 4. Parameters for different SWCC prediction methods

\begin{tabular}{|c|c|c|c|c|c|c|}
\hline Methods & Parameters & KLC & SLC & TSC & TLC & OLC \\
\hline \multirow{5}{*}{$\begin{array}{l}\text { Best-fitted SWCC, } \\
\text { Fredlund and Xing } \\
\text { (1994), Equation } 1\end{array}$} & SWCC ID & KLC-1 & SLC-1 & TSC-1 & TLC-1 & OLC-1 \\
\hline & $a(\mathrm{kPa})$ & 18 & 21 & 15.5 & 19.5 & 63 \\
\hline & $n$ & 6.427 & 1.51 & 2.92 & 1.058 & 3.01 \\
\hline & $m$ & 0.065 & 0.082 & 0.123 & 0.092 & 0.024 \\
\hline & $s_{\text {res }}(\mathrm{kPa})$ & 1500 & 1500 & 1500 & 1500 & 1500 \\
\hline \multirow{5}{*}{$\begin{array}{l}\text { Zapata (1999), } \\
\text { Equation } 2\end{array}$} & SWCC ID & KLC-2 & SLC-2 & TSC-2 & TLC-2 & OLC-2 \\
\hline & $a(\mathrm{kPa})$ & 50 & 63 & 36 & 48 & 189 \\
\hline & $n$ & 1.2 & 1.17 & 1.26 & 1.2 & 1.04 \\
\hline & $m$ & 0.64 & 0.65 & 0.62 & 0.64 & 0.71 \\
\hline & $s_{\text {res }}(\mathrm{kPa})$ & 1889 & 2488 & 1287 & 1833 & 9025 \\
\hline \multirow{5}{*}{$\begin{array}{l}\text { Perera et al. (2005), } \\
\text { Equation } 3\end{array}$} & SWCC ID & KLC-3 & SLC-3 & TSC-3 & TLC-3 & OLC-3 \\
\hline & $a(\mathrm{kPa})$ & 103 & 110 & 90 & 102 & 132 \\
\hline & $n$ & 0.72 & 0.67 & 0.81 & 0.72 & 0.54 \\
\hline & $m$ & 0.25 & 0.21 & 0.34 & 0.26 & 0.06 \\
\hline & $s_{\text {res }}(\mathrm{kPa})$ & 500 & 500 & 500 & 500 & 500 \\
\hline \multirow{6}{*}{$\begin{array}{l}\text { Extended Zapata } \\
\text { (1999), based on } \\
\text { Equation } 2\end{array}$} & SWCC ID & KLC-4 & SLC-4 & TSC-4 & TLC-4 & OLC-4 \\
\hline & $x_{Z}$ & 13.69 & 27.27 & 9.6 & 26.36 & 48.95 \\
\hline & $a(\mathrm{kPa})$ & 89 & 355 & 57 & 326 & 1873 \\
\hline & $n$ & 1.12 & 0.98 & 1.18 & 0.99 & 0.82 \\
\hline & $m$ & 0.67 & 0.74 & 0.65 & 0.74 & 0.81 \\
\hline & $s_{\text {res }}(\mathrm{kPa})$ & 3728 & 19116 & 2191 & 17265 & 151018 \\
\hline \multirow{6}{*}{$\begin{array}{l}\text { Houston et al. } \\
\text { (2006), based on } \\
\text { Equation } 3\end{array}$} & SWCC ID & KLC-5 & SLC-5 & TSC-5 & TLC-5 & OLC-5 \\
\hline & $x_{H}$ & 2.95 & 9.97 & 1.89 & 10.46 & 28.64 \\
\hline & $a(\mathrm{kPa})$ & 68 & 108 & 53 & 110 & 143 \\
\hline & $n$ & 1 & 0.68 & 1.16 & 0.67 & 0.49 \\
\hline & $m$ & 0.48 & 0.22 & 0.58 & 0.21 & -0.008 \\
\hline & $s_{r e s}(\mathrm{kPa})$ & 500 & 500 & 500 & 500 & 500 \\
\hline \multirow{6}{*}{$\begin{array}{l}\text { Chin et al. (2010), } \\
\text { Equation } 4\end{array}$} & SWCC ID & KLC-6 & SLC-6 & TSC-6 & TLC-6 & OLC-6 \\
\hline & $x_{C}$ & 241.7 & 123 & 242.2 & 107.4 & 13.77 \\
\hline & $a(\mathrm{kPa})$ & 142 & 427 & 141 & 464 & 689 \\
\hline & $n$ & 0.63 & 0.48 & 0.63 & 0.45 & 0.2 \\
\hline & $m$ & 0.7 & 0.44 & 0.69 & 0.4 & 0.09 \\
\hline & $s_{\text {res }}(\mathrm{kPa})$ & 564 & 715 & 563 & 737 & 889 \\
\hline
\end{tabular}

